\title{
PRAXIAS IDEOMOTORAS
}

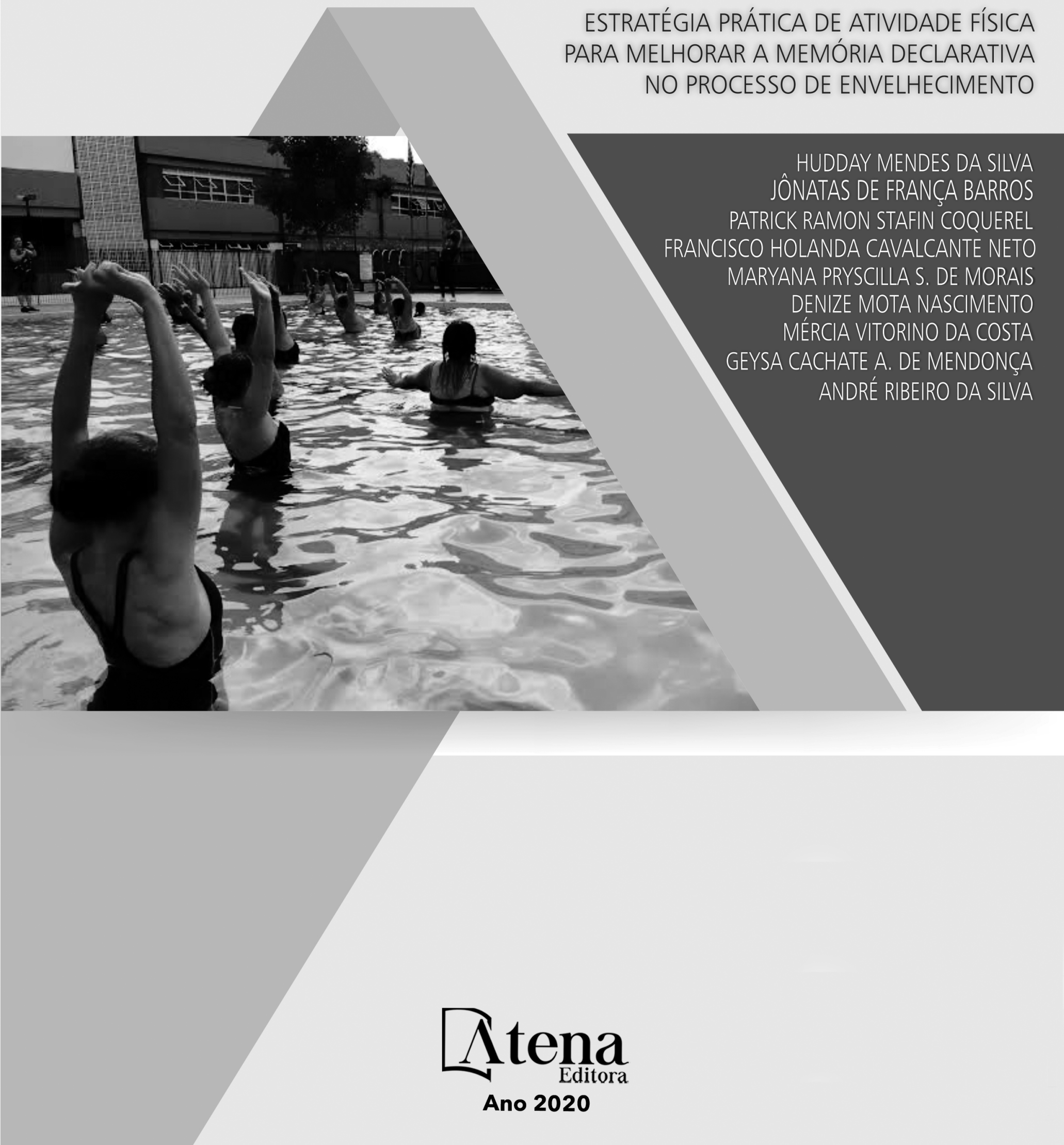




\section{PRAXIAS IDEOMOTORAS}

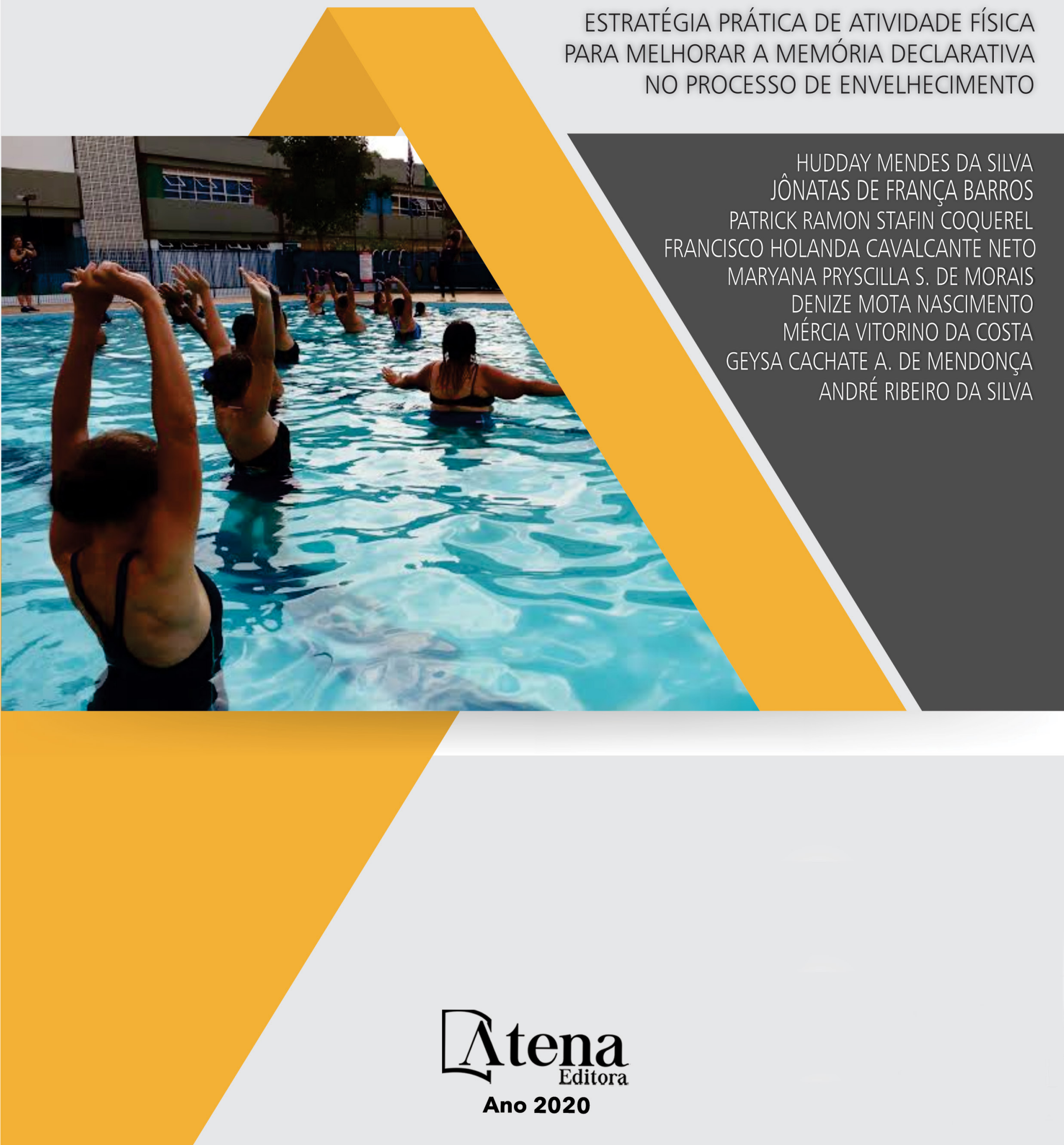




\author{
2020 by Atena Editora \\ Copyright (C) Atena Editora \\ Copyright do Texto (C) 2020 Os autores \\ Copyright da Edição (c) 2020 Atena Editora \\ Editora Chefe: Prof $^{\mathrm{a}} \mathrm{Dr}^{\mathrm{a}}$ Antonella Carvalho de Oliveira \\ Diagramação: Natália Sandrini \\ Edição de Arte: Lorena Prestes \\ Revisão: Os Autores
}

Todo o conteúdo deste livro está licenciado sob uma Licença de Atribuição Creative

Commons. Atribuição 4.0 Internacional (CC BY 4.0).

O conteúdo dos artigos e seus dados em sua forma, correção e confiabilidade são de responsabilidade exclusiva dos autores. Permitido o download da obra e o compartilhamento desde que sejam atribuídos créditos aos autores, mas sem a possibilidade de alterá-la de nenhuma forma ou utilizá-la para fins comerciais.

\title{
Conselho Editorial
}

\section{Ciências Humanas e Sociais Aplicadas}

Prof $^{a}$ Dr $^{a}$ Adriana Demite Stephani - Universidade Federal do Tocantins

Prof. Dr. Álvaro Augusto de Borba Barreto - Universidade Federal de Pelotas

Prof. Dr. Alexandre Jose Schumacher - Instituto Federal de Educação, Ciência e Tecnologia de Mato Grosso

Prof. Dr. Antonio Carlos Frasson - Universidade Tecnológica Federal do Paraná

Prof. Dr. Antonio Gasparetto Júnior - Instituto Federal do Sudeste de Minas Gerais

Prof. Dr. Antonio Isidro-Filho - Universidade de Brasília

Prof. Dr. Carlos Antonio de Souza Moraes - Universidade Federal Fluminense

Prof. Dr. Constantino Ribeiro de Oliveira Junior - Universidade Estadual de Ponta Grossa

Prof $^{\mathrm{a}} \mathrm{Dr}^{\mathrm{a}}$ Cristina Gaio - Universidade de Lisboa

Prof $^{a}$ Dr $^{a}$ Denise Rocha - Universidade Federal do Ceará

Prof. Dr. Deyvison de Lima Oliveira - Universidade Federal de Rondônia

Prof. Dr. Edvaldo Antunes de Farias - Universidade Estácio de Sá

Prof. Dr. Eloi Martins Senhora - Universidade Federal de Roraima

Prof. Dr. Fabiano Tadeu Grazioli - Universidade Regional Integrada do Alto Uruguai e das Missões

Prof. Dr. Gilmei Fleck - Universidade Estadual do Oeste do Paraná

Prof $^{a} \mathrm{Dr}^{\mathrm{a}}$ Ivone Goulart Lopes - Istituto Internazionele delle Figlie de Maria Ausiliatrice

Prof. Dr. Julio Candido de Meirelles Junior - Universidade Federal Fluminense

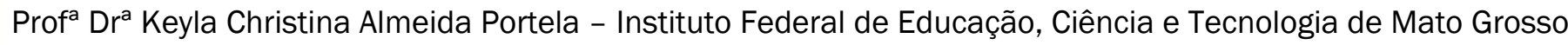

Prof $^{a}$ Dr $^{a}$ Lina Maria Gonçalves - Universidade Federal do Tocantins

Prof $^{a}$ Dr $^{a}$ Natiéli Piovesan - Instituto Federal do Rio Grande do Norte

Prof. Dr. Marcelo Pereira da Silva - Universidade Federal do Maranhão

Prof $^{\mathrm{a}} \mathrm{Dr}^{\mathrm{a}}$ Miranilde Oliveira Neves - Instituto de Educação, Ciência e Tecnologia do Pará

Prof $^{a}$ Dr $^{\text {a }}$ Paola Andressa Scortegagna - Universidade Estadual de Ponta Grossa

Prof $^{a}$ Dr $^{\mathrm{a}}$ Rita de Cássia da Silva Oliveira - Universidade Estadual de Ponta Grossa

Prof $^{a} \mathrm{Dr}^{\mathrm{a}}$ Sandra Regina Gardacho Pietrobon - Universidade Estadual do Centro-Oeste

Prof $^{a}$ Dr $^{\text {a }}$ Sheila Marta Carregosa Rocha - Universidade do Estado da Bahia

Prof. Dr. Rui Maia Diamantino - Universidade Salvador

Prof. Dr. Urandi João Rodrigues Junior - Universidade Federal do Oeste do Pará

Prof $^{a}$ Dr $^{a}$ Vanessa Bordin Viera - Universidade Federal de Campina Grande

Prof. Dr. William Cleber Domingues Silva - Universidade Federal Rural do Rio de Janeiro

Prof. Dr. Willian Douglas Guilherme - Universidade Federal do Tocantins

\section{Ciências Agrárias e Multidisciplinar}

Prof. Dr. Alexandre Igor Azevedo Pereira - Instituto Federal Goiano

Prof. Dr. Antonio Pasqualetto - Pontifícia Universidade Católica de Goiás

Prof $^{\mathrm{a}} \mathrm{Dr}^{\mathrm{a}}$ Daiane Garabeli Trojan - Universidade Norte do Paraná

\section{贝tena


Prof $^{a}$ Dra $^{a}$ Diocléa Almeida Seabra Silva - Universidade Federal Rural da Amazônia

Prof. Dr. Écio Souza Diniz - Universidade Federal de Viçosa

Prof. Dr. Fábio Steiner - Universidade Estadual de Mato Grosso do Sul

Prof. Dr. Fágner Cavalcante Patrocínio dos Santos - Universidade Federal do Ceará

Prof $^{a}$ Dr $^{a}$ Girlene Santos de Souza - Universidade Federal do Recôncavo da Bahia

Prof. Dr. Júlio César Ribeiro - Universidade Federal Rural do Rio de Janeiro

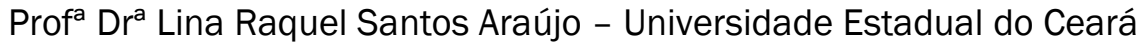

Prof. Dr. Pedro Manuel Villa - Universidade Federal de Viçosa

Prof $^{\mathrm{a}} \mathrm{Dr}^{\mathrm{a}}$ Raissa Rachel Salustriano da Silva Matos - Universidade Federal do Maranhão

Prof. Dr. Ronilson Freitas de Souza - Universidade do Estado do Pará

Prof $^{\mathrm{a}} \mathrm{Dr}^{\mathrm{a}}$ Talita de Santos Matos - Universidade Federal Rural do Rio de Janeiro

Prof. Dr. Tiago da Silva Teófilo - Universidade Federal Rural do Semi-Árido

Prof. Dr. Valdemar Antonio Paffaro Junior - Universidade Federal de Alfenas

\section{Ciências Biológicas e da Saúde}

Prof. Dr. André Ribeiro da Silva - Universidade de Brasília

Prof $^{\mathrm{a}} \mathrm{Dr}^{\mathrm{a}}$ Anelise Levay Murari - Universidade Federal de Pelotas

Prof. Dr. Benedito Rodrigues da Silva Neto - Universidade Federal de Goiás

Prof. Dr. Edson da Silva - Universidade Federal dos Vales do Jequitinhonha e Mucuri

Prof $^{a}$ Dr $^{a}$ Eleuza Rodrigues Machado - Faculdade Anhanguera de Brasília

Prof $^{a} \mathrm{Dr}^{\mathrm{a}}$ Elane Schwinden Prudêncio - Universidade Federal de Santa Catarina

Prof. Dr. Ferlando Lima Santos - Universidade Federal do Recôncavo da Bahia

Prof. Dr. Gianfábio Pimentel Franco - Universidade Federal de Santa Maria

Prof. Dr. Igor Luiz Vieira de Lima Santos - Universidade Federal de Campina Grande

Prof. Dr. José Max Barbosa de Oliveira Junior - Universidade Federal do Oeste do Pará

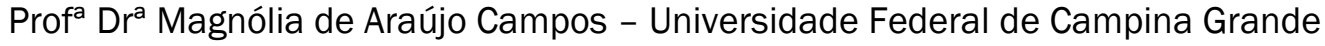

Prof $^{\mathrm{a}} \mathrm{Dr}^{\mathrm{a}}$ Mylena Andréa Oliveira Torres - Universidade Ceuma

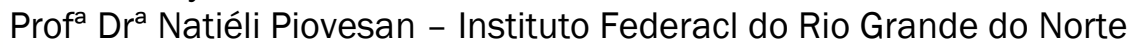

Prof. Dr. Paulo Inada - Universidade Estadual de Maringá

Prof $^{a}$ Dr ${ }^{\mathrm{a}}$ Vanessa Lima Gonçalves - Universidade Estadual de Ponta Grossa

Prof $^{\mathrm{a}} \mathrm{Dr}^{\mathrm{a}}$ Vanessa Bordin Viera - Universidade Federal de Campina Grande

\section{Ciências Exatas e da Terra e Engenharias}

Prof. Dr. Adélio Alcino Sampaio Castro Machado - Universidade do Porto

Prof. Dr. Alexandre Leite dos Santos Silva - Universidade Federal do Piauí

Prof. Dr. Carlos Eduardo Sanches de Andrade - Universidade Federal de Goiás

Prof $^{\mathrm{a}} \mathrm{Dr}^{\mathrm{a}}$ Carmen Lúcia Voigt - Universidade Norte do Paraná

Prof. Dr. Eloi Rufato Junior - Universidade Tecnológica Federal do Paraná

Prof. Dr. Fabrício Menezes Ramos - Instituto Federal do Pará

Prof. Dr. Juliano Carlo Rufino de Freitas - Universidade Federal de Campina Grande

Prof. Dr. Marcelo Marques - Universidade Estadual de Maringá

Prof $^{\mathrm{a}} \mathrm{Dr}^{\mathrm{a}}$ Neiva Maria de Almeida - Universidade Federal da Paraíba

Prof $^{a}$ Dra $^{a}$ Natiéli Piovesan - Instituto Federal do Rio Grande do Norte

Prof. Dr. Takeshy Tachizawa - Faculdade de Campo Limpo Paulista

\section{Conselho Técnico Científico}

Prof. Msc. Abrãao Carvalho Nogueira - Universidade Federal do Espírito Santo

Prof. Msc. Adalberto Zorzo - Centro Estadual de Educação Tecnológica Paula Souza

Prof. Dr. Adaylson Wagner Sousa de Vasconcelos - Ordem dos Advogados do Brasil/Seccional Paraíba

Prof. Msc. André Flávio Gonçalves Silva - Universidade Federal do Maranhão

Prof $^{a} \mathrm{Dr}^{\mathrm{a}}$ Andreza Lopes - Instituto de Pesquisa e Desenvolvimento Acadêmico

Prof ${ }^{a}$ Msc. Bianca Camargo Martins - UniCesumar

Prof. Msc. Carlos Antônio dos Santos - Universidade Federal Rural do Rio de Janeiro

Prof. Msc. Claúdia de Araújo Marques - Faculdade de Música do Espírito Santo

Prof. Msc. Daniel da Silva Miranda - Universidade Federal do Pará

Prof $^{a}$ Msc. Dayane de Melo Barros - Universidade Federal de Pernambuco 
Prof. Dr. Edwaldo Costa - Marinha do Brasil

Prof. Msc. Eliel Constantino da Silva - Universidade Estadual Paulista Júlio de Mesquita

Prof. Msc. Gevair Campos - Instituto Mineiro de Agropecuária

Prof. Msc. Guilherme Renato Gomes - Universidade Norte do Paraná

Prof $^{a}$ Msc. Jaqueline Oliveira Rezende - Universidade Federal de Uberlândia

Prof. Msc. José Messias Ribeiro Júnior - Instituto Federal de Educação Tecnológica de Pernambuco

Prof. Msc. Leonardo Tullio - Universidade Estadual de Ponta Grossa

Prof ${ }^{a}$ Msc. Lilian Coelho de Freitas - Instituto Federal do Pará

Prof $^{a}$ Msc. Liliani Aparecida Sereno Fontes de Medeiros - Consórcio CEDERJ

Prof $^{a}$ Dr $^{a}$ Lívia do Carmo Silva - Universidade Federal de Goiás

Prof. Msc. Luis Henrique Almeida Castro - Universidade Federal da Grande Dourados

Prof. Msc. Luan Vinicius Bernardelli - Universidade Estadual de Maringá

Prof. Msc. Rafael Henrique Silva - Hospital Universitário da Universidade Federal da Grande Dourados

Prof ${ }^{a}$ Msc. Renata Luciane Polsaque Young Blood - UniSecal

Prof ${ }^{a}$ Msc. Solange Aparecida de Souza Monteiro - Instituto Federal de São Paulo

Prof. Dr. Welleson Feitosa Gazel - Universidade Paulista

\begin{tabular}{|c|c|}
\hline & $\begin{array}{c}\text { Dados Internacionais de Catalogação na Publicação (CIP) } \\
\text { (eDOC BRASIL, Belo Horizonte/MG) }\end{array}$ \\
\hline P919 & $\begin{array}{l}\text { Praxias ideomotoras [recurso eletrônico] : estratégia prática de } \\
\text { atividade física para melhorar a memória declarativa no processo } \\
\text { de envelhecimento / Hudday Mendes da Silva... [et al.]. - Ponta } \\
\text { Grossa, PR: Atena Editora, 2020. } \\
\text { Formato: PDF } \\
\text { Requisitos de sistema: Adobe Acrobat Reader } \\
\text { Modo de acesso: World Wide Web } \\
\text { Inclui bibliografia } \\
\text { ISBN 978-65-81740-34-4 } \\
\text { DOI 10.22533/at.ed.677202701 } \\
\text { 1. Aptidão física. 2. Exercícios aeróbicos. 3. Envelhecimento. } \\
\text { 4.Memória. I. Cavalcante Neto, Francisco Holanda. II. Barros, } \\
\text { Jônatas de França. III. Coquerel, Patrick Ramon Stafin. IV. Silva, } \\
\text { Hudday Mendes da. V. Morais, Maryana Pryscilla Silva de. VI. Costa, } \\
\text { Mércia Vitoriano da. VII. Nascimento, Denize Mota. VIII. Mendonça, } \\
\text { Geysa Cachate Araújo de. IX. Silva, André Ribeiro da. } \\
\text { CDD } 613.71\end{array}$ \\
\hline & Elaborado por Maurício Amormino Júnior - CRB6/2422 \\
\hline
\end{tabular}

Atena Editora

Ponta Grossa - Paraná - Brasil

www.atenaeditora.com.br

contato@atenaeditora.com.br 
A Deus, porque tornou tudo possível no tempo e na medida certa.

A minha futura esposa, por sempre me incentivar a acreditar na concretização de sonhos e fundamentalmente pelo apoio afetuoso e carinhoso.

Aos meus pais, que os amos, e sei que nada disso teria acontecido sem o apoio deles e educação dada. Vocês sempre serão minhas inspirações. 


\section{AGRADECIMENTOS}

Ao professor Dr. Jonatas de França Barros, pela valiosa orientação e apoio ao longo desses anos de convívio e trabalho e, principalmente por me incentivar a assumir desafios, acreditando em meu crescimento humano, científico e profissional. A você Jonatas meu eterno e sincero agradecimento.

À todos professores do PPGEF, pelas contribuições essenciais dadas direta e indiretamente nesse trabalho.

À Coordenação de Aperfeiçoamento de Pessoal do Nível Superior (CAPES) pela concessão da bolsa de Mestrado.

Aos professores que fizeram parte da presente banca pelas valiosas contribuições perante a pesquisa.

Aos meus amigos e parceiros do LAFIS e grupos de pesquisa do Curso de Educação Física da Universidade Federal do Rio Grande do Norte pelo apoio e dedicação. 
SUMÁRIO

RESUMO

ABSTRACT

CAPÍTULO 1

INTRODUÇÃO

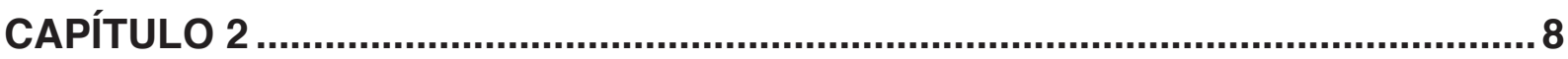

REFERÊNCIA TEÓRICO

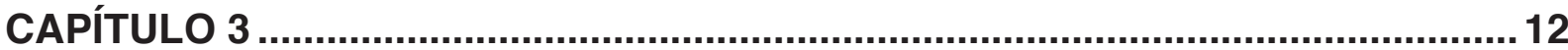

MATERIAIS E MÉTODOS

CAPÍTULO 4

RESULTADOS

CAPÍTULO 5

DISCUSSÃO

CAPÍTULO 6

CONCLUSÃO

REFERÊNCIAS..

ANEXOS

37

APÊNDICES. 46

SOBRE OS AUTORES 50 
Introdução: Diversas modificações são apontadas quanto ao envelhecimento, causando maior ou menor limitação imposta pelo decorrer dos anos. Dentre essas, pode-se destacar os diferentes graus de declínio cognitivo, particularmente da memória, podendo comprometer as atividades diárias e na funcionalidade do sujeito. Estudos demonstram associação entre os níveis de concentração sérica de cortisol e o estresse imposto pelo exercício sobre este. Porém, encontram-se escassos trabalhos que referencie o desempenho em aspectos cognitivos de memória declarativa e cortisol sobre o exercício físico na água com movimentos automáticos e práxicos e de intensidade moderada. Objetivo: Verificar o efeito do exercício agudo baseado em atividade física práxica e automática sobre o desempenho de memória visual declarativa e nas concentrações séricas de cortisol no processo de envelhecimento em sujeitos fisicamente ativos. Materiais e Métodos: Constrói-se uma pesquisa caracterizada como transversal, com uma amostra inicialmente de 32 sujeitos fisicamente ativos com faixa etária compreendidas entre 51 e 74 anos, divididas em dois grupos de exercício (Grupo de Marcha automática - GMA e o Grupo de Marcha Práxica - GMP). Utilizará ainda de uma amostragem probabilística e não aleatória para seleção da amostra. Utilizou-se o MEEM (Mini Exame do Estado Mental) para verificar o estado cognitivo geral (BRUCKI et al., 2003), o teste de acuidade visual - cartela optótipos "E" de Rasquin (ARIPPOL et al., 2006) e ainda foi utilizado o teste de memória visual declarativa proposto por Nitrini et al. (1994), aplicando-se antes da estimulação motora, imediatamente após e após 48 horas da prática, para verificação do efeito tardio; assim, como a realização da coleta sanguínea com $2 \mathrm{ml}$ para análise do hormônio de cortisol. Resultados: Os dois grupos de exercício apresentaram melhoras imediatamente após o estímulo (GMA = 14,7\% e GMP = 10,6\%), porém não foram observadas variações significativas, porém o GMA manteve-se melhoras significativas $(p<0,05)$ quanto aos efeitos tardios (48 horas após). Quanto ao cortisol, as atividades foram moduladoras, diminuindo as concentrações na corrente sanguínea, sendo para o GMA mais efetiva $(p<0,05)$. Conclusão: Pode-se atribuir nesse sentido, que ambas as atividades podem ser recomendadas para prática habitual em adultos velhos e idosos, observando que no que se concerne aos efeitos agudos tanto a marcha automática, quanto a práxica produzem respostas positivas para memória visual declarativa, como também foram capazes de modular os níveis de cortisol, causando imediatamente após o estímulo menor estresse. Mesmo assim, cabe-se investigar maiores efeitos produzidos pelo o exercício práxico e automático no meio aquático sobre as alterações cognitivas 
provocadas pelo o envelhecimento.

PALAVRAS-CHAVE: Idosos; Cortisol; Memória. 
Introduction: Several modifications are identified as aging, causing more or less limitation imposed by over the years. Among these, one can highlight the different degrees of cognitive decline, particularly memory which can involve the daily activities and the subject functionality. Studies have shown an association between levels of serum cortisol and stress imposed by the exercise on this. However, there is little work that references the performance on cognitive aspects of declarative memory and cortisol on the exercise in the water with automatic and práxicos movements and moderate. Objective: To investigate the effect of acute exercise based on praxis and automatic physical activity on the performance of visual declarative memory and in serum cortisol in the aging process in physically active subjects. Materials and Methods: It builds a survey characterized as cross with a sample initially of 32 physically active subjects aged between 51 and 74 years, divided into two exercise group (March Group Automatic - MGA and the March Group Praxis - MGP). You will also use a probabilistic and non-random sampling for sample selection. We used the MMSE (Mini Mental State Examination) to check the overall cognitive status (Brucki et al., 2003), the visual acuity test - optotypes chart "E" Rasquin (ARIPPOL et al, 2006) and still will use the declarative visual memory test proposed by Nitrini et al. (1994), applying before the motor stimulation, immediately after and 48 hours of practice to verify the late effect; as well as the realization of blood collection with $2 \mathrm{ml}$ for analysis of cortisol hormone. Results: Both exercise groups showed improvement immediately after the stimulus (MGA $=14.7 \%$ and $M G P=10.6 \%)$, but was not observed significant variations, but the MGA, remained significant improvements $(p<0,05)$ about the late effects (48 hours). As cortisol, were modulating the activity decreasing concentrations in the bloodstream, and for more effective MGA ( $p$ <.05). Conclusion: You can assign this sense that both activities can be recommended for usual practice in older adults and the elderly, noting that as regards the acute effects both automatic gait, as the praxis produce positive responses to visual declarative memory, as were also able to modulate the cortisol levels immediately after the stimulus causing less stress. Even so, if it is up to investigate major effects produced by the praxis and automatic exercise the aquatic environment on cognitive changes caused by aging.

KEYWORDS: Elderly; Cortisol; Memory. 


\section{CAPÍTULO 1}

INTRODUÇÃO

A população de idosos tem sofrido um aumento considerável quando comparado a estatísticas nacionais em décadas anteriores. O instituto Brasileiro de Geografia e Estatística apresentam dados interessantes, com $4,8 \%$ da população idosa em 1991, passando para 5,9\% em 2000 e chegando em 7,4\% em 2010, estimando ainda que em 2020 esse valor chegue aproximadamente 14,8\%, dobrando o número de pessoas acima de 60 anos (IBGE, 2010).

Observando esse aumento da população idosa, pesquisas destacam-se a fim de investigar problemas relacionados ao desenvolvimento neurofisiológico, estando vulneráveis a declínios significativos de memória, atenção e funções executivas, mesmo os idosos não acometidos de doenças (IRIGARAY; GOMES FILHO; SCHNEIDER, 2012).

Houve um aumento significativo em pesquisas do envelhecimento cognitivo humano nos ultimos 50 anos (YASSUDA et al., 2006). Há consenso, que determinados déficits de memória, atenção e funções executivas também caracterizam o envelhecimento saudável e natural do ser humano (YASSUDA et al., 2006; IRIGARAY, GOMES FILHO, SCHNEIDER, 2012; CHARIGLIONE, JANCZURA, 2013). Essa afirmação é baseada em estudos que demonstraram diferenças entre adultos jovens e idosos em tarefas envolvendo a memória operacional e a memória episódica, mostrando assim, o efeito da idade sobre a memória (STUART-HAMILTON, 2002; YASSUDA; COLS, 2006); ainda, pesquisas relacionadas ao processos mnésicos que observou-se diferenças significativas entre jovens e idosos durante a codificação e o resgate das informações (KAUSLER, 1991); e, evidências que apontam para uma lentidão no processamento das informações em idosos (SALTHOUSE, 1991).

Intervenções que visam à prevenção de doenças e promoção da saúde são alternativas de baixo custo e de grande benefício para a população, principalmente, a idosa (MARTINSON et al., 2003). A prática regular de atividade física tem se mostrado uma importante intervenção e tem sido evidenciado que a inatividade representa um alto custo para a sociedade (WEISS et al.,2004; KRUK, 2009) aumentando ainda mais quando associada ao envelhecimento (PRATT et al., 2000; NUNES, 2004). Então, já é atribuído que a atividade física promove alterações neurofisiológicas e psicológicas que atribuem aos idosos um papel significativo na prevenção e no tratamento de doenças mentais (DESLANDES et al., 2009). 
A praxia ideomotora caracterizam-se como funções neuropisocológicas complexas que correspondem a sistemas de movimentos coordenados em função de um resultado ou intenção (AUBERT; ALBARET, 2001). Nesse sentido, utilizar atividades psicomotoras que envolvem a praxia ideomotora, atividade essas que envolvem os grandes grupos musculares, planificação motora e integração rítmica, desempenham um papel predominante na melhora do comando nervoso, nos refinamentos, das sensações e precepções.

O que encontra-se na literatura específica, é um processo denominado de retrogênese, caracterizado por mudanças nas habilidades psicomotoras que ocorrem de forma inversa à aquisicação do desenvolvimento motor normal. Tais mudanças podem ser observadas ao longo do processo de envelhecimento e também são ilustradas em algumas doenças neurodegenerativas como o Alzheimer e Parkinson (BORGES et al., 2010).

\subsection{Fundamentação do Problema e sua importância}

A preocupação com o envelhecimento deve-se ao fato de os idosos corresponderem a uma parcela cada vez mais representativa da população (NERI; SOARES, 2007). Esse aumento decorre de inúmeros fatores, entre os quais se destacam os avanços e progressos das ciências médicas, associados à diminuição das doenças contagiosas e da natalidade e à melhoria das condições higiênicas e de saúde além de uma crescente consciência da população em relação aos hábitos e preservação das atividades físicas e profissionais (IRIGARAY; GOMES FILHO; SCHNEIDER, 2012).

O que se tem sugerido sobre as possíveis explicações do exercício aeróbico sobre o retardamento do ritmo de declínio das perdas de memória está relacionado principalmente à melhora e bom funcionamento do sistema cerebrovascular, na melhoria da função cardiorrespiratória (capacidade funcional), nas alterações bioquímicas, ou seja, no aumento do transporte de oxigênio para o cérebro, aumento do fluxo sanguíneo (ANTUNES et al., 2001); ainda, no aumento na síntese e degradação de neurotransmissores (que precisam de oxigênio para reações bioquímicas), na diminuição da pressão arterial, das concentrações de colesterol e triglicerídeos (ROBERGS, ROBERTS, 2002); mostra-se também influência na redução do excesso de hormônios suprarrenais, como por exemplo, o cortisol, estando relacionada a níveis altos de estresse (KHALSA, STAUTH, 2001).

Apesar dos benefícios encontrados a partir de aumento do exercício, os adultos mais velhos identificam inúmeros obstáculos à participar de exercícios, incluindo limitações de tempo, falta de motivação/determinação, a falta de familiaridade com as instalações de lazer, medo de cair, má saúde física, osteoartrite e falta de conhecimento sobre o tipo recomendado e intensidade da atividade (COSTELLO et al., 2011; IRVINE et al., 2013; LEES et al., 2005; MATTHEWS et al., 2010; SCHUTZER; GRAVES, 2004; WANG et al., 2007;. WILCOX et al., 2009). Uma 
abordagem alternativa é o uso de programas de exercícios aquáticos, uma vez que coloca menos estresse sobre as articulações de um indivíduo, bem como reduz o risco de queda (HALE; WATERS; HERBISON, 2012). Exercício na água também mostraram ganhos como aumentos nos níveis de aptidão cardiovascular em adultos mais velhos (BOCALINI et al., 2008; BOCALINI et al., 2010; WANG et al., 2007) e através da participação em exercícios na água, os adultos mais velhos são mais capazes de atender às diretrizes para os níveis recomendados de atividade física (BOCALINI et al., 2008; NIKOLAI et al., 2009).

\subsection{Problema da Pesquisa}

Nesse sentido, diante do exposto: Será que praxias ideomotoras apresentam influências na quantificação sérica do cortisol e no desempenho da memória em sujeitos fisicamente ativos com idade compreendida entre 51 e 74 ?

\subsection{Objetivos}

\subsubsection{Objetivo Geral}

Verificar o efeito do exercício agudo baseado em atividade física práxica e automática sobre o desempenho de memória visual declarativa e nas concentrações séricas de cortisol no processo de envelhecimento em sujeitos fisicamente ativos.

\subsubsection{Objetivos Específicos}

- Verificar as respostas do exercício automático e práxico na água sobre o desempenho da memória visual declarativa quanto ao efeito imediato e tardio em 48 horas.

- Verificar os níveis de cortisol sanguíneo imediatamente após e no seu efeito tardio (48h após) a intervenção motora baseada em exercício com praxia e com movimentos automatizados.

\subsection{Hipóteses}

Formulado os objetivos, adotou-se como hipótese verdadeira: "O exercício aeróbio práxico e automático apresentam efeitos significativos com variação negativa para a concentração de cortisol diminuindo assim os efeitos de estresse e apresentando desempenho significativo sobre o teste de memória visual declarativa, assim aumentando a acurácia de respostas corretas"; mostrando efeito contrário a hipótese de nulidade: "O exercício aeróbio práxico e" automático não demonstraram efeitos significativos sobre a variação negativa para a concentração de cortisol, não diminuindo assim os efeitos de estresse e não foi capaz de modular um desempenho significativo sobre o teste de memória visual declarativa, assim não aumentando a acurácia de respostas corretas. 


\subsection{Relevância do Estudo}

O que se observa em relação ao exercício físico, é que o mesmo gera estresse, ativando assim o eixo Hipotálamo-Pituitária-Adrenal (HPA), consequentemente liberando cortisol, hormônio responsável por ações fisiológicas de luta e fuga. Diversos estudos têm mostrado um aumento de cortisol logo após uma única sessão de exercício (DALBO et al., 2011; GOLDSTEIN, KOPIN, 2008). Por outro lado, a prática de exercícios de intensidade e duração moderada promove alterações neurofisiológicas no eixo HPA que podem atenuar a resposta e sensibilidade ao estresse (STRANAHAN, LEE, MATTSON, 2008; TSATSOULIS, FOUNTOULAKIS, 2006), devido ao aumento no número de receptores para cortisol no tecido alvo e melhora na sensibilidade destes receptores (HACKNEY, 2006).

Com o envelhecimento observa-se que diversos fatores sofrem declínio, inclusivo os aspectos da função cognitiva, como por exemplo a memória declarativa. Essas variáveis também podem sofrer variáveis? quando o idoso é exposto a situações desencadeadoras de estresse (LUPIEN; MCEWEN, 1997). Além disso, a exposição crônica a glicocorticoides durante o processo de envelhecimento tem sido associada a volumes reduzidos do hipocampo (região cerebral intrinsecamente envolvida no aprendizado e memória), bem como ao declínio cognitivo (LUPIEN et al., 1998).

Como visto, a magnitude do efeito do exercício físico na cognição depende da natureza da tarefa cognitiva que está sendo avaliada e do tipo de exercício físico que será aplicado. Dessa forma, como principal contribuição verifica-se que exista influência entre a atividade física proposta (automática e práxica) sobre a memória visual declarativa e na modulação do cortisol, no qual já observamos que podem ser modulados pelo estresse que a atividade pode gerar. 


\section{CAPÍTULO 2}

\section{REFERÊNCIA TEÓRICO}

\subsection{Exercício físico e função cognitiva}

Tratando-se do envelhecimento cerebral, o exercício físico constitui um agente neuroprotetor contra as desordens degenerativas do sistema nervoso central. Estudos evidenciam que o exercício físico leva a um aumento da circulação sanguínea cerebral, favorecendo a síntese de neurotrofinas e consequentemente promovendo a criação de novos neurônios em diversas áreas cerebrais (BANHATO et al., 2009). Tais neurotrofinas atuam como mediadoras da eficácia sináptica aumentando a conectividade entre os neurônios.

Diante dessa grande demanda de pesquisas envolvendo a cognição e o exercício físico publicado recentemente, podemos destacar que desde a década de 30 que já vêm tendo essa preocupação (BEISE et al., 1937; BERPEE; STROLL, 1936; LAWTHER, 1955; PIERSON; MONTOYE, 1958). Spirduso (1978) foi o primeiro a pesquisar a relação da atividade física com o envelhecimento cognitivo. Ele investigou a associação do exercício com a cognição em adultos mais velhos, e sugeriu que o exercício aeróbico foi benéfico para o início e execução da ação (BAYLOR, SPIRDUSO, 1988; SPIRDUSO, 1980; SPIRDUSO, CLIFFORD, 1978).

De acordo com Gomez-Pinilla e Hillman (2013), crescentes evidências suportam a influência do exercício na vitalidade e função do Sistema Nervoso Central (SNC) como também promove a resistência contra desordens neurológicas. De acordo com algumas pesquisas, o exercício físico tem a capacidade de melhorar a saúde mental, e os esforços atuais estão sendo dedicados para usar esta capacidade de reduzir a deterioração cognitiva em distúrbios do envelhecimento e psiquiátricos.

Inovações na neuroimagem têm possibilitado a documentação e uma melhor análise na relação entre o ganho cognitivo e a atividade de redes neurais específicas no córtex cerebral, como também no hipocampo humano (PEREIRA et al., 2007). Com essas inovações, a cognição e a atividade física em humanos tem buscado mudanças induzidas pelo exercício em redes que envolvem o córtex pré-frontal e os processos cognitivos associados. Estudos com o hipocampo têm a ponte mais diretamente à diferença entre os modelos humanos e animais, como demonstram pesquisas recentes, superando esta lacuna através de imagens do hipocampo em humanos e examinaram as diferenças no volume desta estrutura e desempenho 
cognitivo relacionado em função do condicionamento aeróbico (BUGG, HEAD, 2011; ERICKSON et al., 2010; ERICKSON et al.,2011). Mais precisamente, Erickson et al. (2010), verificou em 165 idosos cognitivamente saudáveis, a relação entre a capacidade cardiorrespiratória com o volume do hipocampo durante uma tarefa de memória espacial, e observou que quanto maior a aptidão, maior a associação entre o volume do hipocampo e melhor desempenho na memória espacial. Esses resultados sugerem que a aptidão aeróbica pode ser um meio eficaz para prevenção da cárie cortical relacionada à idade e o déficit cognitivo (ERICKSON et al.,2011).

A compreensão dos mecanismos pelos quais o exercício físico afeta as habilidade cognitivas tem sido alimentada a partir de várias frentes?. Para GomezPinilla e Hilman (2013), o exercício tem demonstrado uma extraordinária aptidão para influenciar vias moleculares envolvidas com a função sináptica da aprendizagem subjacente e memória. Dada a relação intrínseca entre o exercício e o metabolismo energético, não é tão surpreendente que a modulação de sistemas moleculares relacionadas com a energia pareça ser um mecanismo fundamental pelo qual os exercícios afetam a plasticidade sináptica e a cognição. Nessa linha, o Brain-Derived Neurotrophic Factor (BDNF), na interface do metabolismo e da plasticidade sináptica, pode desempenhar um papel crucial para identificar a melhoria cognitiva induzida pelo o exercício. Assim, a aptidão do exercício de impactar os sistemas moleculares envolvidos com o metabolismo e plasticidade sináptica que podem sustentar a função mental. Assim, esses mecanismos desempenham um papel crucial na mediação de efeitos do exercício sobre o envelhecimento e em doenças neurodegenerativas.

O cérebro tem uma capacidade notável para modificar sua estrutura e função de acordo com as influências do ambiente e da experiência. A atividade física tem desempenhado um papel de muita importância durante esse processo de adaptação biológica e de sobrevivência das espécies durante milhares de anos, num processo no qual o cérebro moderno foi desenvolvido. Assim, o hipocampo, uma estrutura que tem um papel fundamental no processamento de memória é uma das principais regiões do cérebro influenciada pela atividade física (GOMEZ-PINILLA; HILMAN, 2013).

Em uma meta-análise realizada por Colcombe e Kramer (2003), verificaram a relação entre treinamento aeróbico e cognição em idosos com idade compreendida entre 55 e 80 anos de idade e 18 pesquisas evidenciaram que o exercício físico aumenta o desempenho cognitivo. Outra meta-análise recentemente publicada (SMITH et al., 2010) corroborou com Colcombe e Kramer (2003), onde o exercício aeróbico foi relacionada com a atenção, velocidade de processamento, memória e controle cognitivo.

O exercício aeróbico melhora significativamente várias funções cognitivas que normalmente se deterioram com o envelhecimento, tais como a memória (ANTUNES et al.,2001; BANHATO et al., 2009; PESCE et al., 2009). 


\subsection{Memória e atividade física}

Se tratando de meios de tratamento para doenças cognitivas, que envolvem a memória como parte afetada por essas, a atividade física merece uma atenção especial como meio de intervenção, um complemento que tem muitos benefícios para saúde, podendo servir para uma melhora na qualidade de vida (PLASSMAN et al., 2010).

Em uma revisão realizada no Cochrane Database, observou-se que onze ensaios clínicos aleatórios demonstraram que o exercício aeróbio melhora a cognição em alguns domínios, incluindo a velocidade cognitiva, auditiva e a atenção visual (MAAIKE et al., 2008). Em outra revisão apresentada no estudo de Forbes et al. (2008), apenas duas pesquisas se mostraram relevantes, porém o mesmo concluiu que não havia provas suficientes de benefícios a partir do exercícios em pacientes sem nenhum comprometimento cognitivo.

Estudos já evidenciam efeitos benéficos em animais e em humanos sobre a prática da atividade física em relação a melhora cognitiva e de memória (VAN PRAAG et al., 1999; VAYNMAN et al., 2006; WINTER et al., 2007). Ruscheweyh et al. (2011) visualizando os achados, preocupou-se em verificar o efeito que a intensidade do exercício físico apresenta sobre a memória episódica, e constatou que o desempenho da memória episódica pode ser melhorada através da prática de atividade física com intensidade baixa.

A perda de memória e atrofia cerebral são muitas vezes consideradas marcas do envelhecimento. Mas nem todas as formas de memória são igualmente afetadas pela idade (FLEISCHMAN et al., 2004; HEDDEN, GABRIELI, 2004); da mesma forma, nem todas as regiões do cérebro mostram atrofia relacionada à idade (FJELL, WALHOVD, 2010). A atividade física tem atraído maior atenção nos últimos anos como sendo um método potencialmente eficaz para elevar a função cognitiva, como também melhorar a saúde do cérebro ao longo da vida. Nesse sentido, um estilo de vida fisicamente ativo pode aumentar a probabilidade de envelhecimento cerebral bem-sucedida e atenuar a probabilidade de um envelhecimento cerebral acelerado (ERICKSON; LECKIE; WEINSTEIN, 2014).

Algumas revisões apoiam a alegação de que a atividade física tem um forte efeito sobre a saúde do cérebro, ressaltando ainda que há muito a se aprender sobre as maneiras que a atividade física pode ser utilizada como prevenção e/ou tratamento para uma perda de volume cerebral e como consequência uma melhora nos aspectos cognitivos, como por exemplo, a memória declarativa (BROWN et al., 2013; GUINEY; MACHADO, 2013; SHERDER et all., 2013; ERICKSON et all., 2012). 


\subsection{Cortisol e Exercício Físico}

O cortisol é um hormônio esteroide que é produzido e segregado na zona fasciculada adrenal do córtex adrenal. É o principal glicocorticoide endógeno (ARNALDI et al., 2003). O cortisol é regulado a níveis circulantes, pelo o eixo hipotálomo-hipófise adrenal (HPA) e por um circuito de realimentação neuroendócrino que pode ser ativada por estímulos psicofisiológicos como por exemplos, estresse, síndrome de Cushing, a depressão e pelo exercício (PAULI et al., 2006; PAPACOSTA, NASSIS, 2011).

O estresse é um termo que pode ser usado para descrever o conjunto de reações desenvolvidas pelo corpo humano, quando sujeitas a uma situação que requer esforço para gerar adaptação, associação com o cortisol, dar-se pela influência no metabolismo celular mobilizando as fontes de energia para o uso em situações de estresse, modulando a proteólise, gliconólise, gliconeogênese e lipólise (PEREIRA et al., 2004). O estresse ainda pode ser definido como uma forma de deterioração geral provocada por alterações psicofisiológicas que ocorrem quando um indivíduo é exposto a estímulos potencialmente prejudiciais (excitação emocional, esforço excessivo, fadiga, dor, medo e concentração) (TRAUSTADÓTTIR, BOSCH, MATT, 2005).

A resiliência relaciona-se com a capacidade de adaptação e recuperação do estresse, porém, o observa-se com o envelhecimento que essa capacidade diminui gradativamente. Essa redução na capacidade de responder ao estresse com o envelhecimento está relacionada, em parte, pela anormalidade na função do eixo HPA que podem resultar na liberdade de grandes quantidades de cortisol e outros componentes do eixo HPA, tais como o corticotropina (CHECKLEY, 1996).

O exercício, como já mencionado, é um estressor ao organismo, pois resulta em aumento da demanda de energia e cria um desequilíbrio na homeostase energética. Diferentes tipos de exercícios modulam efeitos sobre os níveis hormonais, e o que se destaca é que o exercício de força apresenta magnitudes maiores (KRAEMER, RATAMESS, 2005) em relação ao aeróbio (VALE et al., 2009). O mesmo acontece quando se verifica a intensidade observando respostas diferentes entre exercícios moderados e intensos (MORAES et al., 2012). De acordo com Stranahan, Lee, Mattson (2008) exercícios moderados promovem alterações neurofisiológicas no eixo HPA que podem atenuar a resposta e sensibilidade ao estresse.

Assim, o cortisol resposta varia em relação ao tipo e intensidade do exercício, nível de formação estado nutricional e nível de estresse. Em relação ao exercício agudo, essas relações têm sido extensivamente estudadas em uma variedade de grupos de idade e parece promover um aumento nos níveis de cortisol (CONTARTEZE et al., 2007). 


\section{CAPÍTULO 3}

\section{MATERIAIS E MÉTODOS}

\subsection{Caracterização do Estudo}

Esta pesquisa é de natureza aplicada, com tratamento de dados quantitativos e do tipo transversal (THOMAS; NELSON, 2002), apresenta ainda uma amostragem probabilística classificada como aleatória simples, na qual abre possibilidade de todos os sujeitos da amostra serem selecionados para quaisquer grupos de intervenção Grupo de Marcha Automática/Grupo Marcha Práxica (Rumsey, 2012).

\subsection{População do estudo}

Foram recrutadas 40 sujeitas voluntárias, de ambos os sexos e distribuídos em grupos etários, envolvendo adultos jovens e idosos (de 51 a 74 anos). Todos participantes já inerentes de um projeto de extensão/pesquisa (Cód. PVD 8630/2012) há no mínimo 6 meses de prática de exercício aeróbio no meio aquático, coordenado pelo o Laboratório de Atividade Física e Saúde (LAFIS), no qual está inserido no Núcleo de Saúde e Desenvolvimento Humano (NSDH) do Departamento de Educação Física (DEF) e da Universidade Federal do Rio Grande do Norte, foram classificados como fisicamente ativos por apresentarem frequência $\geq 75 \%$ nas sessões de exercício, apresentando uma prática regular semanal de aproximadamente 150 min de atividade moderada, ocorrendo em uma frequência de 3 vezes semanais, com microciclos que variam progressivamente de 30 a $50 \mathrm{~min} / \mathrm{sessão.} \mathrm{Todos} \mathrm{os} \mathrm{sujeitos}$ estavam aptos à prática de exercício físico mediante um atestado médico.

Após serem convenientemente informados sobre a proposta do estudo, procedimentos, benefícios e riscos aos quais seriam submetidos, os participantes assinaram o Termo de Consentimento Livre e Esclarecido (APENDICE B). Constase ainda que a presente pesquisa foi aprovada pelo Comitê de ética e Pesquisa da Universidade Federal do Rio Grande do Norte - UFRN, com parecer n 719.271, na data de 30 e maio de 2014, estando totalmente de acordo com as normas da Resolução CNS. 466/12.

Foram distribuídos os sujeitos de forma aleatória em dois grupos, o primeiro o grupo de Marcha automática - GMA $(n=16)$ e o segundo grupo o de Marcha Práxica - GMP $(n=16)$. Para isso utilizou-se de uma técnica de amostragem randomizada controlada, portanto, trata-se de uma amostragem tipo probabilística, onde todos 
os sujeitos da população que atendam os critérios de inclusão terão as mesmas oportunidades de compor a amostragem (VIEIRA, 1980).

A presença de sujeitos com doenças crônicos degenerativas (TABELA01), como Diabetes Mellitus 2 e Hipertensão, foram incluídos na amostras por apresentarem níveis controlados e não fazerem uso de medicamentos que pudessem interferir nos resultados dos testes. Segundo Vargas, Lara, Mello-Carpes (2014), diabetes mellitus associado com a um estilo de vida ativo, com prática de exercício físico e atividades recreativas provavelmente não seria um fator de risco para perdas cognitivas significativas associadas ao processo de envelhecimento. Estudo realizado por Mayeda, Whtimer, Yaffe (2015) afirma que idosos que têm um melhor controle glicêmico apresentam menores riscos de desenvolver demência. No estudo de Glodzik et al. (2014), não houve diferença em relação a biomarcadores, volumes do hipocampo e nem pontuação no teste de memória entre normotensos e hipertensos, sugerindo que para o presente estudo a população hipertensa não cause nenhuma alteração em relação aos resultados.

\subsubsection{Critérios de Inclusão}

- Sujeitos inseridos no projeto de extensão/pesquisa de prática de exercício aeróbio na água baseado em marcha automática a no mínimo 6 meses, para controle do nível de atividade física, com média de 150 min semanais com intensidade leve a moderada, conforme as normas propostas pela ACMS (2001).

- Apresentar exames médicos o liberando para prática de exercício físico atualizado atestando suas condições para se submeter a esforços moderados.

- Não realizar atividade física extenuante, ingerir bebida alcóolicas e bebidas cafeinadas nas últimas 48 horas.

- Apresentar doenças crônicas degenerativas, como diabetes mellitus e hipertensão, devidamente controladas.

\subsubsection{Critérios de Exclusão}

- $\quad$ Não está dentro da faixa etária recomendada pela pesquisa (entre 51 e 77 anos);

- Possuir frequência inferior a 75\% dentro do projeto de extensão/pesquisa de exercício aeróbio na água baseado em marcha automático;

- Fazer uso de medicamentos com reconhecidos efeitos sobre o desempenho cognitivo, o que inclui a memória;

- Possuir lesão ou ter realizado alguma cirurgia ortopédica recentemente, com interferência direta na marcha;

- Ter diagnóstico de doença neurológica; 
- Atingir pontuação inferior a 24 no Mini Exame de Estado Mental;

- Possuir acuidade visual comprometida.

\subsection{Procedimentos Gerais}

\subsubsection{Protocolos de estimulação}

Após aplicar-se os critérios de inclusão e exclusão os grupos alguns sujeitos foram eliminados por não atenderem aos critérios estabelecidos pela presente pesquisa, podendo assim, a vir influenciar nos resultados. Como já mencionado, após seguir os critérios foram selecionados no total de 32 sujeitos, sendo assim, eliminados 8, 2 por assumir uma acuidade visual comprometida, 3 por não cumprir todas as fases da pesquisa e 3 por terem atingindo valores inferiores a 19 no MEEM, mostrando-se prejuízo cognitivo. De acordo com a distribuição, obteve-se 16 sujeitos no GMA e 16 no GMP, com idade respectiva de 64,4 \pm 3,8 anos e 61,7 \pm 6,4 anos.

Os grupos foram submetidos a protocolos de exercício físico diferente no meio aquático. A piscina utilizada para estímulo agudo tem espessuras de $25 \times 12,5 \times$ $1,5 \mathrm{~m}$ (piscina semiolímpica). Os sujeitos realizaram a atividade com água na altura do peito. De acordo com Silva Filho, Fernandes e Lobo da Costa (2005) atividades aquáticas são mais indicadas para populações mais velhas por conta de apresentar um ambiente redutor de impacto e apresentar índice de lesão minimizado, além de propiciar efeitos na melhoria do humor e na motivação para prática de exercício físico, assim, inibindo desistência e estimulando assim o sedentarismo para essa população.

Os protocolos foram organizados em duração e intensidade igual, sendo distribuído em 5 minutos de aquecimento mediante marcha automática, em ambos os grupos, e 30 minutos de exercício físico, onde o GMA realizou durante os 30 minutos exercício de marcha automático e para o GMP foi distribuído movimentos práxicos (APÊNDICE A), movimentos esses que foram selecionados e programados para não se repetir durante a sessão, e sendo organizados com alternância a cada 60 seg., esses por vez apresentaram mudança de direção, de segmento corporal e ainda se fez o uso de músicas para determinar ritmo ao movimento. Esses movimentos são entendidos por Fonseca (2008), movimentos voluntários, consciente, intencional, organizado e inibido, sujeito, portanto, a um planejamento cortical e a um sistema de auto regulação.

Ainda cabe-se destacar que as estimulações foram realizadas de forma simultâneas no processo de duplo cego, visto que o profissional que aplicou o teste de memória não tinha conhecimento de qual grupo o sujeito estaria participando quanto a estimulação automática ou práxica.

Para verificar-se a intensidade utilizou-se da Escala de BORG de 6 a 20 (BORG, 1980), sendo apresentada aos participantes a cada $10 \mathrm{~min}$. A Escala de 
Valência Afetiva - EVA (HARDY; REJESKI, 1989), na qual apresenta o objetivo de observar o monitoramento do prazer ou desprazer, é quantificada de +5 a -5 , correspondendo, respectivamente, aos dois descritores antagônicos do sentimento durante a atividade física: "muito bom" e "muito ruim", além destes, a escala apresenta descritores intermediários: +3 = bom; +1 = razoavelmente bom; 0 = neutro; -3 = ruim; -1 = razoavelmente ruim, e dessa forma foi proposto que o afeto durante o estímulo motor para ambos os grupos se mantivesse como +3 "bom" (valor selecionado pelos pesquisadores), onde sugere-se que o eixo hipotálamo-hipófise-adrenal é um sistema dinâmico influenciado por alterações no afeto negativo (BUCHANAN; AL'ABSI; LOVALLO, 1999), como ainda identifica-se que maiores níveis de cortisol são produzidos durantes atividades com afeto negativo (PIAZZA at all., 2013).

Como observado na figura abaixo, a organização da coleta de dados, deu-se no período de $48 \mathrm{~h}$ contados desde o momento Baseline, com a aplicação do teste de memória (Nitrini et all, 1994) e coleta sanguínea (dosagem do cortisol), logo após, a estimulação motora (Marcha automática para o grupo GMA e marcha práxica para o grupo GMP), com duração de 35 minutos, onde em seguida era realizada uma nova aplicação do teste de memória e coleta sanguínea, e após $48 \mathrm{~h}$ repete-se o procedimento de aplicação de teste de memória e coleta sanguínea para verificar o efeito tardio do exercício sobre as variáveis dependentes. Lembra-se ainda que todas coletas foram realizadas no mesmo horário entre 7 h00min e 9h00min.

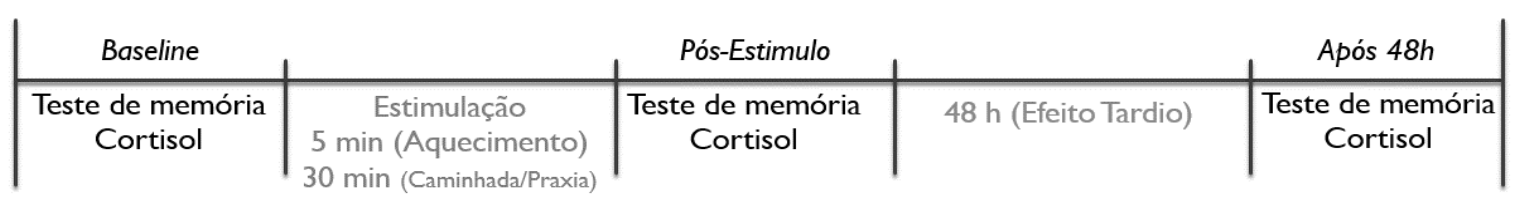

Figura 01: Desenho metodológico da sessão de coleta de dados.

\subsubsection{Mini Exame de Estado Mental (MEEM)}

Desde sua publicação inicial por Folstein et al. (1975) tem-se utilizado o MiniExame do Estado Mental (MEEM) de forma clínica para detectar perdas cognitivas, no seguimento evolutivo de doenças e no monitoramento de resposta a tratamentos e como instrumento de pesquisa, tem sido largamente empregado em estudos epidemiológicos populacionais integrando diversas baterias neuropsicológicas.

Dessa forma, o MEEM é um instrumento clássico empregado para rastrear a presença ou não de comprometimento cognitivo em população idosa (BERTOLUCCI et al., 1994; FOLSTEIN et al., 1975). Composto por questões agrupadas em sete categorias, cada uma delas planejada com o objetivo de avaliar "funções" cognitivas específicas como a orientação temporal (5 pontos), orientação espacial (5 pontos), registro de três palavras (3 pontos), atenção e cál culo (5 pontos), recordação das 
três palavras (3pontos), linguagem (8 pontos) e capacidade construtiva visual (1 ponto). O escore do MEEM pode variar de um mínimo de 0 pontos, o qual indica o maior grau de comprometimento cognitivo dos indivíduos, até um total máximo de 30 pontos, o qual, por sua vez, corresponde a melhor capacidade cognitiva. Há vários estudos normativos para a população brasileira que levam em consideração a idade e escolaridade dos sujeitos (KOCHHAM et al., 2010; LAKS et al., 2007; LOURENÇO et al., 2008; LOURENÇO; VERAS, 2006). Os escores para identificar possíveis problemas cognitivos e possível demência foram baseado nos de Murden et al. (1991), onde para sujeitos com mais de 9 anos de estudo o corte era de 24 ponto e para menores escolaridades 17 pontos.

\subsubsection{Acuidade Visual (Teste de Optótipo "E")}

O seguinte teste foi realizado com o intuito de verificar a acuidade visual por meio da tabela direcional optotipos " $E$ ", essa avaliação é formada por uma tabela com 12 fileiras com 5 letras cada, com tamanho das letras variando em progressão logarítmica de 1,0 logMAR (20/200) a, 1 logMAR (20/10), com valores normativos para não comprometimento na acuidade visual de uma escala de 20/60 (0,33 logMAR) em um dos olhos. O espaçamento entre letras em cada fileira mantém a mesma largura das letras e, o espaçamento entre fileiras, corresponde ao tamanho das letras da menor fileira. Essa avaliação é amplamente utilizada por ser compreendida por alfabetizados e não alfabetizados, sendo de fácil aplicação e baixo custo (Arippol; Salomão; Belfort Junior, 2006). O teste será realizado com o indivíduo sentado a uma distância de três metros da tela de um monitor de 14 polegadas, no nível dos olhos do avaliado. O indivíduo deve indicar para qual direção (para cima, para baixo, para a direita ou para a esquerda) aponta a porção aberta da letra "E". A avaliação visual será feita com cada olho separadamente, não utilizando lentes corretivas, visto os sujeitos não efetuarem o exercício físico com elas.

\subsubsection{Teste de Memória Visual Declarativa}

O teste de memória proposto por Nitrini et al. (1994) é composto pela memorização de 10 figuras, na qual os sujeitos primeiramente serão indagados: Que figuras são essas? O escore é dado pelo número de figuras corretamente identificadas mesmo que não tenham sido adequadamente denominadas, esse procedimento será para percepção visual. Para memória incidental, o procedimento é avaliado com a pergunta: Que figuras eu lhe mostrei? O escore é dado pelo número de resposta certas. E a memória após 5 minutos, será verificada mostrando novamente a folha na qual contém as figuras durante 30 segundos dizendo: Quais as figuras desenhadas que eu lhe mostrei há 5 minutos? O escore é dado pelo número de respostas certas. 
Para não acontecer de somar resultados cumulativos entre os momentos de aplicação do questionário de memória, foi proposta uma adaptação ao instrumento sendo modificadas as imagens apresentadas nos momentos pré-estimulação (ANEXO B) e pós-estimulação (ANEXO C) e mantendo as imagens originais para o momento de 48 horas após (ANEXO D).

\subsubsection{Cortisol}

A dosagem de cortisol sérico foi avaliada nos momentos do Baseline (cortisol basal), contanto com jejum de 7 horas, pós-estímulo (automático e práxico) e 48 horas após o estímulo, foram coletados $2 \mathrm{ml}$ sanguíneo. Foi utilizado o método de quimioluminescência (Cortisol Immulite 2000, Dianostic Products Corporation - DPC, Los Angeles, CA, EUA) com limite de detecção de $5 \mu \mathrm{g} / \mathrm{dL}$, e avaliado no laboratório integrado de análises clínicas do departamento de análises clínica da Universidade Federal do Rio Grande do Norte (UFRN). O valor basal de referência pela manhã é de 5 a $25 \mu \mathrm{g} / \mathrm{dL}$.

\subsection{Comitê de Ética}

O projeto foi apreciado e aprovado pelo Comitê de Ética da Universidade Federal do Rio Grande do Norte, conforme determina a resolução $n^{\circ} 466 / 12$ do Conselho Nacional de Saúde, sob número de parecer 719.271 (ANEXO E).

Aos participantes da pesquisa e seus responsáveis serão garantidos:

- o esclarecimento, antes e durante a pesquisa, sobre seus propósitos e métodos utilizados;

- o sigilo que assegure a sua privacidade quanto às informações fornecidas;

- o respeito aos valores culturais, sociais, morais, religiosos e éticos, bem como aos seus hábitos e costumes.

Para tanto procurou-se:

- prever procedimentos que assegurem a confidencialidade e a privacidade, a proteção da imagem e a não estigmatizarão, garantindo a não utilização das informações em prejuízo das pessoas, inclusive em termos de autoestima e de prestígio;

- contar com o consentimento livre e esclarecido dos responsáveis pelos participantes da pesquisa.

\subsection{Tratamento Estatístico}

A normalidade e a homogeneidade das variâncias dos dados foram testadas utilizando-se os de testes de Shapiro-Wilke Levene, respectivamente. Posteriormente utilizou-se do software SPSS for Windows versão 20.0, para análise descritiva dos dados oriundos da avaliação da Memória Visual Declarativa e da concentração sérica do cortisol, sendo expressos em médias e desvio padrão. 
Verificado a normalidade e homogeneidade dos dados, foi gerada uma estatística inferencial com ANOVA Two Way para medidas repetidas, seguindo um "Post-Hoc" Bonferroni. Para o cálculo amostral, aplicou-se o poder estatístico (1- $\beta$ ) a priori, utilizando-se da análise de comparação empregada (ANOVA de medidas repetidas), um effect size de $\mathrm{f}^{2}=0,33$ e um alfa de $5 \%$. Para tanto, o poder estatístico conferido a presente amostra foi de $80 \%$ (power $=0,80$ ). Adotou-se nível de significância de $p<0,05$. 


\section{CAPÍTULO 4}

RESULTADOS

A seguir estão expressos os resultados obtidos no presente estudo, os quais estão organizados de forma a evidenciar as análises mediante a memória visual declarativa e o cortisol.

\subsection{Caracterização Demográfica da Amostra}

Pode-se observar na tabela abaixo, as características demográficas quanto as variáveis antropométricas e em relação a função cognitiva mediante o MEEM (FOLSTEIN et al., 1975). O que se observa é que os grupos, para nenhuma variável, apresentaram diferenças significativas $(p>0,05)$, mostrando médias homogêneas.

Cabe destacar, que em percentual dentro da amostra identificou-se sujeitos hipertensos e diabéticos, sendo que diabéticos apenas para o grupo automático. Ressalta-se ainda que os hipertensos presentes na pesquisa controlassem seus níveis de pressão arterial baseadas apenas em exercício físico regular e dieta, assim não fazendo uso de medicamentos. Os sujeitos com doenças degenerativas envolvido na amostra apresentaram taxas normalizadas tanto de pressão arterial como os níveis de glicose.

Outro aspecto relevante a ser destacado é quanto aos resultados médios obtidos em relação ao MEEM, no qual diante o instrumento, os sujeitos não apresentam prejuízo cognitivo por depressão e nem demência; Ainda, destaca-se que para o nível de escolaridade, nenhum sujeito foi identificado com menos de 4 anos, assim não comprometendo a avaliação da memória visual declarativa.

Outro teste descrito é o teste de Optótipos "E" (acuidade visual), que demonstra dados normais para classificação da acuidade visual nos sujeitos de ambos os grupos (Automática $=0,85 \pm 0,2$; Práxica $=0,43 \pm 0,1$ ), seguindo os critérios propostos pela Organização Mundial de Saúde (OMS), não comprometendo assim a prática nem a avaliação durante os estímulos automático e práxico. 


\begin{tabular}{lccc}
\hline & Automática & Práxica & p-valor \\
\hline Sexo (masc./fem.) & $4 / 12$ & $5 / 11$ & - \\
Diabetes Tipo II (\%) & 6,25 & - & - \\
Hipertensos (\%) & 18,5 & 25,0 & - \\
Idade (anos) & $64,4 \pm 3,8$ & $61,7 \pm 6,4$ & 0,234 \\
MC (kg) & $71,1 \pm 7,7$ & $74,5 \pm 19,0$ & 0,530 \\
Estatura (cm) & $157,5 \pm 8,7$ & $156,9 \pm 7,2$ & 0,850 \\
IMC (kg·m-2) & $28,8 \pm 3,6$ & $29,9 \pm 5,5$ & 0,554 \\
CC (cm) & $96,4 \pm 7,7$ & $93,7 \pm 17,2$ & 0,606 \\
CQ (cm) & $102,5 \pm 9,7$ & $103,2 \pm 12,4$ & 0,893 \\
CA (cm) & $99,0 \pm 8,3$ & $100,7 \pm 13,1$ & 0,699 \\
RCQ & $0,9 \pm 0,1$ & $0,9 \pm 0,1$ & 0,364 \\
GC (\%) & $34,4 \pm 10,9$ & $37,9 \pm 9,1$ & 0,321 \\
MEEM (pontos) & $25,2 \pm 1,3$ & $26,4 \pm 2,5$ & 0,196 \\
Escolaridade (anos) & $10,6 \pm 1,5$ & $10,9 \pm 1,9$ & 0,458 \\
Acuidade visual (logMAR) & $0,85 \pm 0,2$ & $0,43 \pm 0,1$ & 0,206 \\
\hline
\end{tabular}

Tabela 1: Características antropométricas, cognitiva e de acuidade visual dos grupos de marcha automática $(n=16)$ e práxica $(n=16)$. Dados expressos em média e $( \pm)$ desvio padrão.

MC - Massa Corporal; IMC - índice de massa corporal; CC - circunferência de cintura; CQ - circunferência de quadril; CA - circunferência de abdômen; RCQ - relação cintura-quadril; GC - gordura corporal; MEEM - Mini Exame de Estado Mental.

\subsection{Desempenho dos grupos (GMA e GMP) na tarefa de Memória Visual Declarativa}

A figura 02 apresenta a acurácia (\%) de respostas corretas nas fases pré, pós e 48 h após o estímulo para cada grupo (GMA e GMP) na tarefa de memória visual declarativa. Observado os resultados da ANOVA para medidas repetidas, identificou-se que houve variação entre os momentos de aplicação no Teste de Memória Visual declarativa $\left[\mathrm{F}_{(2,90)}=3,83, p=0,02\right]$, indo de encontro à hipótese verdadeira, que os estímulos motores (GMA e GMP) influenciaram nos resultados dos testes significativamente. Quanto aos grupos, identificou que não houve variação significativa $\left[\mathrm{F}_{(2,90)}=0,05, \mathrm{p}=0,82\right]$, mostrando assim, que diferenças entre os estímulos não pode ser observado na presente pesquisa. E quando apresentado as interações entre os grupos e os momentos, constatou-se que não existiu variação significativa $\left[F_{(2,90)}=2,58, p=0,08\right]$, assumindo assim, a hipótese nula, onde não haveria diferenças significativas ao comparar os grupos (GMA e GMP) e os momentos (Pré - Pós - 48h após o estímulo).

Aplicado o teste de post hoc, pode-se destacar que o momento pré e $48 \mathrm{~h}$ após o estímulo motor para o grupo de marcha automático, apresentou diferença significativa $(p<0,05)$, melhorando a sua acurácia de respostas corretas após 48 horas, mostrando que a estimulação com marcha automatizada seria mais eficaz para a memória visual declarativa do que a práxica, isso em relação ao efeito tardio; visto, que não foi observado diferença significativas para os demais momentos, apesar de ambos os grupos ter mostrado aumento das médias com ganhos percentuais (GMA 
$=14,7 \%$ e GMP = 10,6\%) nos momentos pré e pós.

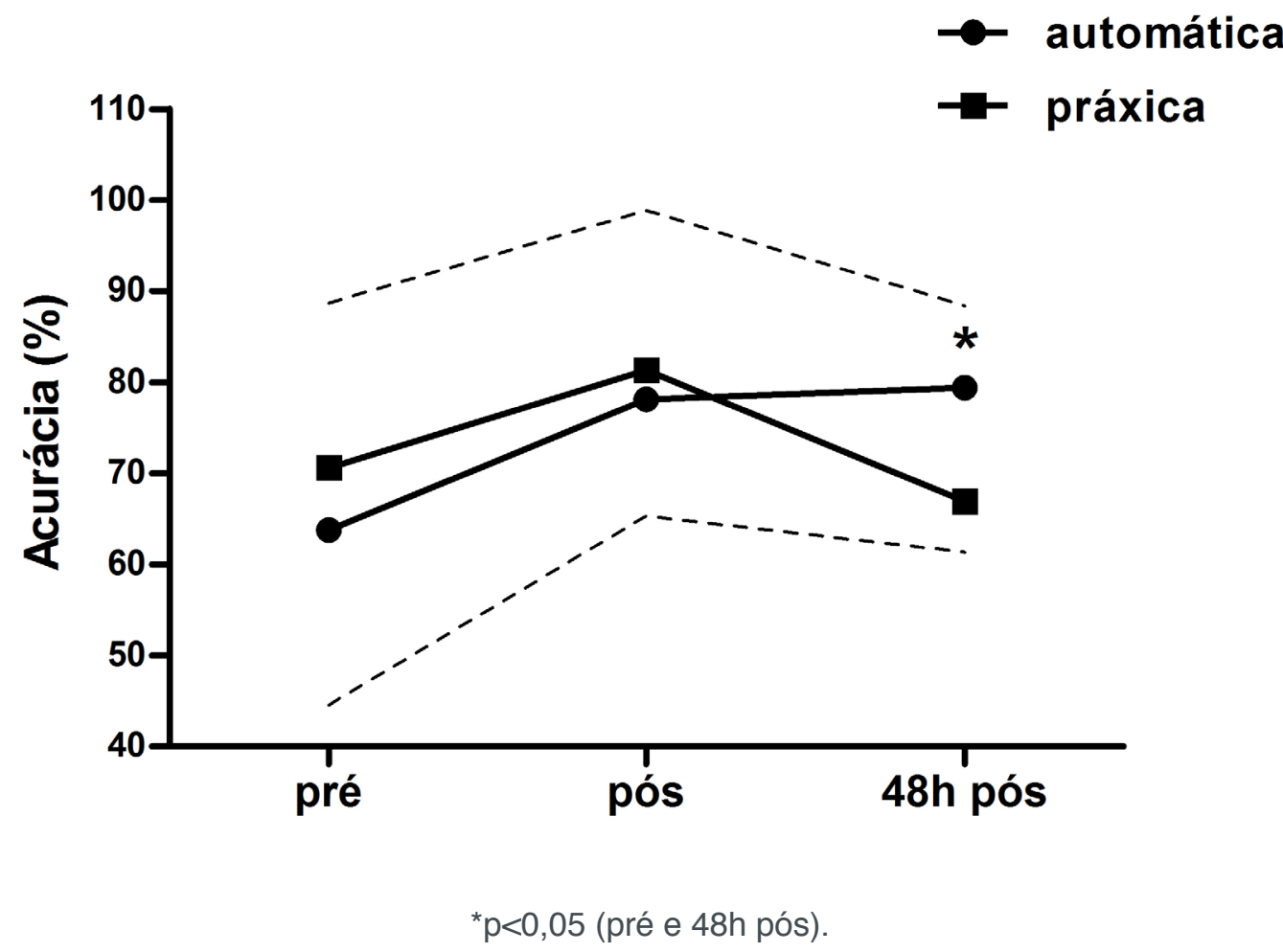

Figura 02: Respostas corretas quanto a tarefa de Memória Visual Declarativa entre os grupos de marcha práxica e automática e os momentos aos quais foram aplicados (pré, pós e $48 \mathrm{~h}$ pós).

\subsection{Análise das concentrações séricas do cortisol}

Para verificar a modulação do cortisol mediante o estímulo motor práxico e automático observaram as possíveis variações entre grupos, momentos e entre ambos.

O que se pode destacar dessa análise, é que a resposta do cortisol apresentou variações significativas tanto entre os grupos de estímulos motores $[F(1,90)=5,32$, $p=0,02]$, como nos momentos pré, pós e 48h pós os estímulos $[F(2,90)=12,56, p=$ 0,001], assim, pode-se assumir a hipótese verdade, onde o exercício aeróbico, sendo ele práxico ou automático, podem modular as concentrações de cortisol séricas na corrente sanguínea. Quando visto a interação entre grupo e momento não se pode destacar o mesmo, não foi identificado variações significativas ao cruzar os grupos e momentos $[F(2,90)=0,08, p=0,92]$. 


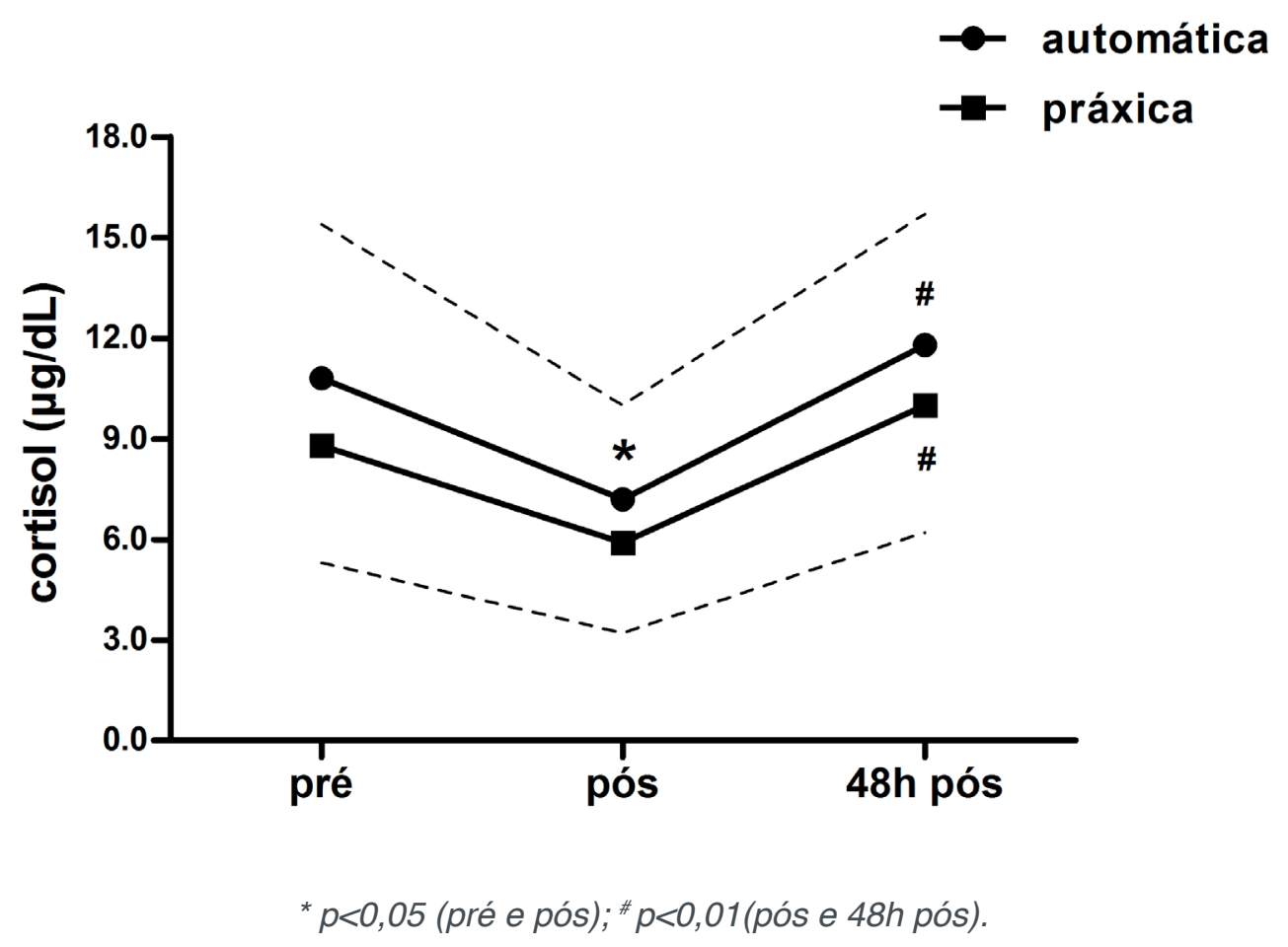

Figura 03: Concentrações séricas de cortisol sanguíneo entre os grupos entre os grupos de marcha práxica e automática e os momentos aos quais foram aplicados (pré, pós e 48h pós).

A dinâmica observada na figura 03 demonstra modulações do Cortisol em relação aos momentos de coleta, e alguns destaques para as variações significativas.

No momento Baseline (pré-estímulo), os valores apresentados pelos sujeitos em ambos os grupos, estão de acordo com o recomendado para as referências basais, automático $x=10,83 \pm 4,5 \mu \mathrm{g} / \mathrm{dL}$ e práxico $x=8,8 \pm 3,4 \mu \mathrm{g} / \mathrm{dL}$, o mesmo acontece no momento pós-estímulo $x=11,7 \pm 3,9 \mu \mathrm{g} / \mathrm{dL}$ e $x=9,9 \pm 3,8 \mu \mathrm{g} / \mathrm{dL}$.

Como destacado na imagem acima, apenas o grupo automático no momento pré e pós-estímulo apresentou variação significativa $(p<0,05)$, sendo associado que a atividade física automatizada diminui de forma efetiva os níveis de cortisol na corrente sanguínea, o mesmo acontece na macha com movimentos práxicos, mas de forma não significativa; ainda, relacionado aos testes de post hoc, o momento pós e 48h pós o exercício também apresentaram resultados significativos para ambos os grupos $(p<0,01)$, entendendo-se assim que após 48 horas do exercício proporcionado aos sujeitos, os níveis de cortisol voltam a subir na corrente sanguínea, ficando bem próximo dos valores basais. 


\section{CAPÍTULO 5}

DISCUSSÃO

A literatura aponta de forma contundente que os mecanismos fisiológicos e bioquímicos subjacentes ao estabelecimento da memória estão sujeitos aos efeitos de diversos fatores internos e externos, como por exemplo, os determinados por doenças, utilização de determinados fármacos ou substâncias psicoativas, dentre outras. A seguir serão discutidos os aspectos sobre atividade física automática e práxica em relação a modulação da memória e das concentrações séricas de cortisol.

\subsection{Efeitos do exercício agudo sobre a memória}

Os resultados apontados na presente pesquisa, destaca que embora os dois grupos analisados tenham apresentado melhora na memória visual declarativa pósexercício, estas não foram significativas. O grupo de marcha automática apresentou diferença significativa frente ao efeito tardio com um período de 48 horas após a estimulação $(p<0,05)$. Com isso entende-se que perante os dois tipos de atividades propostas, a automática torna-se mais efetiva para a variável memória visual declarativa em relação à práxica.

Estudos que analisem o efeito do exercício sobre a função cognitiva em adultos velhos e comparem exercícios automáticos com exercícios que exijam uma aprendizagem motora mais apurada são escassos. O presente estudo analisou em um mesmo ambiente, práticas motoras diferentes quando a quantidade de habilidades motoras envolvidas. Os grupos já apresentavam adaptação quanto à atividade automática, desde então já existia uma pro-atividade cerebral, i.e., uma memória cerebral para realizar a tarefa, e, portanto, uma menor necessidade de ativação de áreas cerebrais para realização da tarefa (LENT, 2008). Este fator está relacionado ao efeito duradouro e positivo na memória visual declarativa, pois a plasticidade gerada pós-atividade física acontece de forma bem menos acentuada, essa por vez é gerada quando alteramos padrões diferentes do habitual, sejam eles motores e/ou cognitivos. No que concerne ao grupo de marcha práxica, esta plasticidade teve que ser gerada em áreas motoras e cognitivas, o que pode ter reduzido seus resultados imediatamente após $48 \mathrm{~h}$ após o exercício.

Um estudo recente explica a influência do exercício sobre os aspectos cognitivos (MEREGE FILHO, et al., 2014). Nele, estabelece relações ao exercício de forma aguda e crônica. De forma aguda, pressupõe que os efeitos do exercício 
sobre a resposta cognitiva sejam mediados por aumentos no fluxo sanguíneo cerebral e, por conseguinte, no aporte de nutrientes, ou por aumento na atividade de neurotransmissores. De forma crônica, especula-se que o exercício possa promover adaptações em estruturas cerebrais e plasticidade sináptica que culminariam com melhoras cognitivas, como foi observado por Tamura et al. (2014), que comprova que o exercício gerou plasticidade em áreas relacionadas a cognição e estas perduraram por um determinado tempo pós a prática.

De acordo com os resultados da presente pesquisa, observou-se aumentos imediatamente após o estímulo motor quanto as respostas corretas (GMA =14,7\% e GMP $=10,6 \%$ ), talvez isso dê-se devido a teoria do aumento do fluxo sanguíneo em diversas áreas corticais, sendo provocado esse aumento em ambas estimulações, assim entende-se que o exercício contribui para o aumento na síntese e na utilização de diversos neurotransmissores (ANTUNES et al., 2006; EGGERMONT et al., 2006), como a serotonina, a dopamina, a acetilcolina e a neropinefrina (SARBADHIKARI, SAHA, 2006).

Respostas cardiovasculares acontecem durando o exercício físico, como o aumento da frequência cardíaca, da pressão arterial e do débito cardíaco ambos ocorrem para que o sistema cardiovascular promova um aumento do fluxo sanguíneo nos músculos exercitados e também nos órgãos mais ativos durante o exercício, como cérebro. Esse aumento de fluxo sanguíneo desencadeia uma série de processos, como por exemplo, o aumento na produção do óxido nítrico, um forte dilatador dos vasos sanguíneos, assim melhorando a vascularização e o fluxo sanguíneo cerebral (DI FRANCESCOMARINO et al., 2009); Assim, pode-se afirmar que perfusão cerebral tenha ocorrido durante a estimulação motora práxica e automática fazendo com que o cérebro receba a quantidade adequada de oxigênio e glicose.

Utilizou-se a intervenção de exercícios aquáticos, visto estes proporcionarem os mesmos benefícios fisiológicos que os exercícios terrestres, porém com redução do risco de lesão aguda. Para comprovar isso, Fedor, Garcia, Gunstad (2015), ao realizar um experimento com 60 idosos, sendo um grupo experimental (6 dias consecutivos de atividades aeróbicas na água/intensidade moderada) e um controle (realizavam suas atividades normais); assim, destacou-se que o grupo exercício melhorou significativamente a aptidão cardiovascular, bem como a função executiva, a atenção e memória, acontecendo o mesmo ao nossos estudos no que se diz respeito ao efeito tardio para o grupo automático. Outros efeitos podem ser atrelados ao exercício aeróbico no meio aquático, como a qualidade de vida e sintomas depressivos (SCHUCH et al., 2014; TAHERI, IRANDOUST, 2014).

Baseado na teoria da retrogênese, na qual mudanças nas habilidades psicomotoras que ocorrem de forma inversa à aquisição do desenvolvimento motor normal (FONSECA, 1998), justificou-se ofertar uma intervenção baseada na praxia. E com sua grande relação à intervenções de dupla tarefa, na qual os movimentos são baseados em desempenhos simultâneos e envolve a execução de uma tarefa 
primária e secundária ao mesmo tempo (O'SHEA, MORRIS, LANSEK, 2002), criouse a hipótese de que essa variável independente pudesse vir a apresentar resultados significativos perante os aspectos relacionados a memória, como apresentado em estudos envolvendo a dupla tarefa (PATEL, LAMAR, BHATT, 2014; BUENO et al., 2014; LOPES et al., 2013). Mesmo não apresentando variação significativa para acurácia da quantidade de acerto, observa-se através das médias que não apenas o grupo de marcha automática aumentou, mas ambos os grupos.

A teoria da hipofrontalidade transiente vem sendo apresentada, para justificativa de pesquisas que não conseguiram visualizar variações significativas em relação a efeitos agudos e crônicos do exercício sobre aspectos cognitivos. Esse modelo sugere que durante a realização do exercício há um aumento da ativação neural para executar os movimentos motores, ampliando as funções receptivas (i.e., na capacidade de selecionar, adquirir, classificar e integrar as informações, como sensação, percepção, atenção e concentração), porém durante o exercício há um redirecionamento do fluxo sanguíneo cerebral para áreas motoras e uma relativa diminuição de fluxo sanguíneo para áreas associadas com as funções cognitivas como as do córtex frontal (DIETRICH, 2006). Esses dados não foram comprovados ao presente estudo, visto os dois estímulos terem apresentado melhoras nas acurácias para quantidade de respostas corretas. Assim, identifica-se que estudos ainda demonstram limitações quanto as técnicas subjetivas para comprovação dessa teoria, sendo necessário mais estudos (WANG et al., 2013; DIETRICH, AUDIFFREN, 2011; DIETRICH, SPARLING, 2004).

\subsection{Efeitos agudo do exercício sobre as concentrações séricas no cortisol}

Fica claro que uma única sessão de exercício físico aeróbico é capaz de modular substancialmente o desempenho cognitivo, e que a intensidade na qual o exercício físico é realizado pode justificar em partes tal condição (KASHIHARA et al., 2009). Kashihara (2009) expõe a ideia que a relação entre a ativação do sistema nervoso central e a intensidade do exercício funciona da forma de «U invertido»; i.e., a intensidade poderia modular efeitos benéficos em importantes funções cognitivas com o exercício moderado (YANAGISAWA et al., 2010), o que foi de encontro com os achados na presente pesquisa, como também, ao ser realizado sobre uma intensidade alta poderia apresentar efeitos prejudiciais sobre a cognição (ANDO et al., 2011), sugerindo-se um quadro de fadiga sistêmica para justificar essa teoria (TOMPOROWSKI, 2003).

Com o objetivo de investigar mecanismos biomoleculares envolvidos no modelamento das estruturas cerebrais e na maior plasticidade sináptica, inúmeras pesquisas envolvendo o modelo animal com métodos invasivos tem-se destacado, investigando sobre a neurogênese, surgimentos de novas conexões sinápticas e proliferação de novos capilares cerebrais baseando na realização de treinamento aeróbio (RHYU et al., 2010). O que se tem observado é que essas alterações parecem 
ocorrer por ações de importantes ações hormonais, como por exemplo, hormônios que exercem funções de estímulo e crescimento neuronal (insuline growth factor I IGF-I e Vascular Endothelial Growth Factor - VEGF) e outros que podem exercer um papel deletério no sistema nervoso central, tal como o Cortisol (MEREGE FILHO et al., 2014).

Portanto, o presente estudo, objetivou verificar o efeito dos estímulos motores práxicos e automático com intensidade moderada sobre o hormônio cortisol. O que se pode observar é que ambos os estímulos modularam de forma a diminuir as concentrações imediatamente após os exercícios, sendo mais efetivado para o grupo de marcha automática. De acordo com Anish (2005) e Armstrong e VanHeest (2002), o exercício pode ter influenciado o eixo endócrino hipotalâmico-hipofisárioadrenocortical (HPA), causando adaptações nas glândulas adrenais reduzindo a liberação de cortisol e corticosterona. Então, o que se pode destacar em relação a essa variável é que tanto a marcha práxica quanto a automática podem ser estratégias moduladoras de redução de cortisol, potencializando adaptações cognitivas.

Optou-se por analisar o cortisol sérico, porque estes apresentam receptores em estruturas límbicas relacionadas à resposta afetiva (p.e., hipocampo, hipotálamo e amígdala) e em regiões centrais de função executiva, como o córtex pré-frontal e o córtex cingulado anterior (DEDOVIC et al., 2009; DE KLOET et al., 2005). Segundo Ebner et al. (2013), existem divergências sobre a concentração de cortisol e a cognição. Estudos envolvendo humanos, mostraram associações negativas entre os níveis de endógenos de cortisol de manhã e medidas de velocidades de processamento cognitivo (ROSA NETO et al., 2010) e função executiva (SCHLOSSER et al., 2013), bem como a aprendizagem espacial (MEYER et al., 2013). Quanto ao efeito do cortisol sobre a memória, as evidências são ambíguas, sugerindo que os efeitos rápidos de cortisol podem levar a alterações da contextualização na memória emocional e efeitos lentos conferem proteção contra a generalização da memória emocional (SCHWABE et al., 2012; VAN AST et al., 2013). As justificativas para esse antagonismo de resultados são que enquanto que enquanto o cortisol (induzido pela experiência estressante ou administração aguda) aparece para aumentar a consolidação da memória, isso mais vezes prejudica a recuperação da memória, porém, essa associação pode ser modificada por fatores disposicionais e situacionais, tais como a excitação emocional e/ou experiência anterior.

Achados semelhantes foram observados por Baker et al. (2010), investigando o efeito de um programa de exercício físico aeróbico sobre a função cognitiva e os níveis de concentração sérica de cortisol em adultos velhos e idosos, destacando que para as mulheres o cortisol reduziu. Dessa forma, entende-se assim que o sexo pode vir a influenciar. O mesmo foi observado por Heaney, Carroll e Phillips (2013). Isso pode justificar o desenho do cortisol visto a amostra ser composto substancialmente por um número de mulheres maior que de homens.

Embora observado nas características da amostra da pesquisa, os sujeitos 
enquadram-se na faixa de sobrepeso e obesidade de acordo com o IMC e porcentagem de gordura. Apesar de a literatura relatar que a obesidade eleve os níveis de cortisol na corrente sanguínea, devido a regulação anormal do eixo HPA ou, eventualmente, de modulações periféricas que ainda estão apenas parcialmente compreendidas (JOHNSON, MILNER, MAKWSKI, 2012), estudos relatam que seu turnover (degradação do hormônio) também é aumentada, assim, as taxas de cortisol aparecem dentro da taxa de normalidade ou até mesmo reduzidas; com isso, podese observa que os indivíduos apresentaram taxas basais dentro da normalidade (MATOS, MOREIRA, GUEDES, 2003). Nesse sentido, estudos com obesos e efeito agudo do exercício aeróbio na água não foram encontrados na literatura, assim não sendo explicado o real mecanismo do cortisol durante o processo de exercício, mas, o que se pode observar na presente pesquisa é que os níveis de percentual de gordura assim como o IMC não modularam o aumento logo após o estímulo, porém, pode ser uma justificativa para os resultados do cortisol 48 horas após. 


\section{CAPÍTULO 6}

CONCLUSÃO

A presente pesquisa objetivou verificar os efeitos que o exercício físico aeróbico aquático baseado em marcha automática e com praxia sobre o desempenho na memória visual declarativa e na concentração sérica de cortisol sanguíneo ao efeito imediato e tardio em 48 horas.

Com isso, observou-se que o efeito imediato do exercício para as variáveis dependentes apresentou-se efetivo, mostrando alterações para o ganho em respostas corretas pelo o teste de memória visual declarativa, mesmo não sendo significativa para ambos os grupos. Isso se pode está vinculado ao processo de aumento de fluxo sanguíneo cerebral produzido pelo exercício aeróbico. Os valores de cortisol reduziram imediatamente após os estímulos, sendo significativo apenas para o grupo automático. Essa resposta pode estar associada a influência que o exercício proporciona no eixo endócrino hipotalâmico-hipofisário-adrenocortical, causando adaptações nas glândulas adrenais reduzindo a liberação do cortisol.

O que se pode concluir com a presente pesquisa, é que tanto a estimulação motora baseada em marcha automática quanto práxica com intensidade moderada, podem influenciar na modulação das concentrações séricas de cortisol como no desempenho de memória visual declarativa.

Nesse sentido, sugere-se novas investigações envolvendo a estimulação motora práxica, para verificar-se efeitos nos aspectos da função cognitiva, mudanças na aptidão física e em marcadores fisiológicos, como hormônio relacionado à neurogênese (IGF - I), a neurotrofina relacionada ao fator de crescimento nervoso (Brain-Derived Neurotrophic Factor - BDNF) e marcadores relacionados ao estresse que o exercício pode promover, como por exemplo o cortisol. 
AMERICAN COLLEGE OF SPORTS MEDICINE. ACSM stand position on the appropriate intervention strategies for weight loss and prevention of weight regain for adults. Med Sci Sports Exerc; 33:2145$56,2001$.

ANDO, S.; KOKUBU, M.; YAMADA, Y.; KIMURA, M. Does cerebral oxygenation affect cognitive function during exercise? Eur J Appl Physiol; 111(9):1973-82, 2011.

ANISH, E.J. Exercise and its effects on the central nervous system. Curr Sports Med Rep.;4(1):18-23, 2005.

ANTUNES, H. K., SANTOS, R. F., CASSILHAS, R., SANTOS, R. V., BUENO, O. F., \& MELLO, M. T. L. D. Exercício físico e função cognitiva: uma revisão. Revista Brasileira de Medicina do Esporte, 12(2), 108-114, 2006.

ANTUNES, H.K.M.; SANTOS, R. F.; HEREDIA, R. A. G.; BUENO, O. F. A.; MELLO, M. T. Alterações cognitivas em idosas decorrentes do exercício físico sistematizado. Revista da Sobama, v. 6, n. 1, p. 27-33, 2001.

ARIPPOL, P.K.K.; SALOMÃO, S.R.; BELFORT JR, R. Método computadorizado para medida da acuidade visual. Arq. Bras. Oftalmol. 69(6):907-14, 2006.

ARMSTRONG, L.E.; VANHEEST, J.L. The unknown mechanism of the overtraining syndrome - Clues from depression and psychoneuroimmunology. Sports Med.; 32(3):185-209, 2002.

ARNALDI, G.; ANGELI, A.; ATKINSON, A.B.; BERTAGNA, X.; CAVAGNINI, F.; CHROUSOS, G.P.; FAVA, G.A.; FINDLING, J.W.; GAILLARD, R.C.; GROSSMAN, AB, KOLA, B.; LACROIX, A.; MANCINI, T.; MANTERO, F.; NEWELL-PRICE, J.; NIEMAN, L.K.; SONINO, N.; VANCE, M.L.; GIUSTINA, A.; BOSCARO, M. Diagnosis and complications of Cushing's syndrome: a consensus statement. $J$ Clin Endocrinol Metab 12:5593-5602, 2003.

AUBERT, E.; ALBARET, J.M. Aspects psychomoteurs du vieillissement normal. In: AUBERT, E.; Albaret, J.M. (Edits.), Vieillissement et psychomotricité. Marseille: Solal, 2001.

BAKER, L.D.; FRANK, L.L.; FOSTER-SCHUBERT, K.; GREEN, P.S.; WILKINSON, C.W.; MCTIERNAN, A. Effects of aerobic exercise on mild cognitive impairment: a controlled trial. Archives of neurology.;67(1):71-9, 2010.

BANHATO, E. F., SCORALICK, N. L. N., GUEDES, D. V., ATALAIA-SILVA, K. C., \& MOTA, M. R. M. Atividade física, cognição e envelhecimento: estudo de uma comunidade urbana. Psicologia: Teoria e Prática, 2009, 11(1), 76-84.

BAYLOR AM, SPIRDUSO WW. Systematic aerobic exercise and components of reaction time in older women. J Gerontol. 1988;43:121-126. 
BEISE, D.; PEASELEY, V. The relationship of reaction time, speed, and agility of big muscle groups and certain sport skills. Research Quarterly.;8:133-142, 1937.

BERTOLUCCI, P. H. F. et al. O mini-exame do estado mental em uma população geral: impacto da escolaridade. Arquivos de Neuropsiquiatria; 52, 1-7, 1994,

BOCALINI, D.S.; SERRA, A.J.; MURAD, N.; LEVY, R.F. Water versus land-based exercise effects on physical fitness in older women. Geriatrics \& Gerontology International, 8, 265- 271, 2008.

BOCALINI, D.S.; SERRA, A.J.; RICA, R.L.; SANTOS, L. ().Repercussions oftraining and detraining by water-based exercise on functional fitness and quality of life: A short-term follow-up in healthy older women. Clinics, 65, 1305- 1309, 2010.

BORG, G. A. V. The perception of physical performance. In: SHEPHARD, R. Frontiers of fitness. Springfi eld: Charles C. Thomas, 1980.

BORGES, S.M.; APHAHAMIAN, I.; RADANOVIC, M.; FORLENZA, O.V. Psicomotricidade e retrogênese: considerações sobre o envelhecimento e a doença de Alzheimer. Rev Psiq Clín.;37(3):131-7, 2010.

BROWN, B.M., PEIFFER, J.J., MARTINS, R.N. Multiple effects of physical activity on molecular and cognitive signs of brain aging: can exercise slow neurodegeneration and delay Alzheimer's disease? Mol. Psychiatry 18, 864-874, 2013.

BUCHANAN, T.W.; AL'ABSI, M.; LOVALLO, W.R. Cortisol fluctuates with increases and decreases in negative affect. Journal of Psychoneuroendocrinology. Vol. 24, Issue, 2, 227-241, 1999.

BUCHMAN, A. S.; BOYLE, P. A.; WILSON, R. S.; BIENIAS, J. L.; BENNETT, D. A. Physical activity and motor decline in older persons. Muscle Nerve, v. 35, p. 354-362, 2007.

BUENO, M.E.B.; ANDRELLO, A.C.R; TERRA, M.B.; ALMEIDA, I.A.; LEMES, L.B.; BATISTETTI, C.L.; SANTOS, S.S. Efetividade da Fisioterapia com Treinamento de Dupla Tarefa no Sistema Motor e Cognitivo em Indivíduos com Doença de Parkinson. Saúde e pesquisa. v. 7, n. 2, 2014.

BUGG, J.M.; HEAD, D. Exercise moderates age-related atrophy of the medial temporal lobe. Neurobiol Aging.;32:506-514, 2011.

CHARIGLIONE, I.P.F.; JANCZURA, G.A. Contribuições de um treino cognitivo para a memória de idosos institucionalizados. Psico-USF, Bragança Paulista, v. 18, n. 1, p. 13-22, jan./abril 2013

CHECKLEY, S. The neuroendocrinology of depression and chronic stress. BMJ 52:597-617, 1996.

COLCOMBE S, KRAMER AF. Fitness effects on the cognitive function of older adults: A meta-analytic study. Psychol Sci. 2003;14:125-130.

CONTARTEZE, R.V.L.; MACHADO, F.B.; GOBATTO, C.A.; MELLO, M.A.R. () Biomarcadores de estresse em ratos exercitados por natação em intensidade igual ou superior à máxima fase estável de lactato. Rev Bras Med Esporte; 13:169-174, 2007.

COSTELLO, E.; KAFCHINSKI, M.; VRAZEL, J.; SULLIVAN, P. Motivators, barriers, and beliefs regarding physical activity in an older adult population. Journal of Geriatric Physical Therapy, 34, 138-147, 2011.

DALBO, V.J.; ROBERTS, M.D.; HASSELL, S.E. Effects of age on serum hormone concentrations and intramuscular proteolytic signaling before and after a single bout of resistance training. J Strength Cond Res; 25(1):1-9, 2011. 
DE KLOET, E.R.; SIBUG, R.M.; HELMERHORST, F.M.; SCHMIDT, M. Stress, genes and the mechanism of programming the brain for later life. Neurosci. Biobehav. Rev. 29, 271-281, 2005. doi: 10.1016/j.neubiorev.2004.10.008

DEDOVIC, K.; DUCHESNE, A.; ANDREWS, J.; ENGERT, V.; AND PRUESSNER, J. C. The brain and the stress axis: the neural correlates of cortisol regulation in response to stress. Neuroimage 47, 864-871, 2009. doi: 10.1016/j.neuroimage.2009.05.074

DESLANDES, A; MORAES, H.; FERREIRA, C. Exercise and mental health: many reasons to move. Neuropsychobiology, 59(4):191-8, 2009.

DIETRICH, A. Transient hypofrontality as a mechanism for the psychological effects of exercise. Psychiatry Research, 145(1), 79-83, 2006.

DIETRICH, A.; AUDIFFREN, M. The reticular-activating hypofrontality (RAH) model of acute exercise. Neuroscience and Biobehavioral Reviews, 35, 2011.

DIETRICH, A.; SPARLING, P. (). Endurance exercise selectively impairs prefrontaldependent cognition. Brain and Cognition, 55(3), 516-524, 2004.

EBNER, N.C.; MAURA, G.M.; MACDONALD, K.; WESTBERG, L.; FISCHER, H. Oxytocin and socioemotional aging: current knowledge and future trends. Front. Hum. Neurosci. 7:487, 2013. doi: 10.3389/fnhum.2013.00487

ERICKSON, K.I.; PRAKASH, R.S.; VOSS, M.W.; CHADDOCK, L.; HU, L.; MORRIS, K.S.; WHITE, S.M.; WÓJCICKI, T.R.; MCAULEY, E.; KRAMER, A.F. Aerobic fitness is associated with hippocampal volume in elderly humans. Hippocampus; 19:1030-1039, 2009

ERICKSON KI, VOSS MW, PRAKASH RS, BASAK C, SZABO A, CHADDOCK L, KIM JS, HEO S, ALVES H, WHITE SM, WOJCICKI TR, MAILEY E, VIEIRA VJ, MARTIN SA, PENCE BD, WOODS JA, MCAULEY E, KRAMER AF. Exercise training increases size of hippocampus and improves memory. Proc Natl Acad Sci U S A. 2011;108:3017-3022.

ERICKSON KI; LECKIE, R.L.; WEINSTEIN, A.M. Physical activity, fitness, and gray matter volume. Neur. Of again, 32 (2), 2014, 20-28.

ERICKSON, K.I., WEINSTEIN, A.M., LOPEZ, O.L. Physical activity, brain plasticity, and Alzheimer's disease. Arch. Med. Res. 43, 615-621, 2012.

FEDOR, A.; GARCIA, S.; GUNSTAD, J. The effects os a brief, water-based exercicise intervention on cognitive function in older adults. Arch Clin Neuropsychol, 2015.

FJELL, A.M., WALHOVD, K.B. Structural brain changes in aging: courses, causes and cognitive consequences. Rev. Neurosci. 21, (2010), 187-221.

FLEISCHMAN, D.A., WILSON, R.S., GABRIELI, J.D., BIENIAS, J.L., BENNETT, D.A. A longitudinal study of implicit and explicit memory in old persons. Psychol. Aging 19, (2004) 617-625.

FOLSTEIN, M.F.; FOLSTEIN, S.E.; MCHUGH, P.R. Mini-Mental State: a practical method for grading the cognitive state of patients for clinician. J Psychiatr Res;12:189-198, 1975.

FONSECA, V. Da Ontogênese à Filogênese da Motricidade. Artes Médicas: Porto Alegre. 1998.

GLODZIK, L.; RUSINEK, H.; PIRRAGLIA, E.; MACHUGH, P.; TSUI, W.; WILLIAMS, S.; CUMMINGS, M.; LI, Y.; RICH, K.; RANDALL, C.; MOSCONI, L.; OSORIO, R.; MURRAY, J.; ZETTERBERG, H.; BLENNOW, K.; LEON, M. Blood pressure decrease correlates with tau pathology and memory decline 
GOLDSTEIN, D.S.; KOPIN, I.J. Adrenomedullary, adrenocortical, and sympathoneural responses to stressors: a meta-analysis. Endocr Regul; 42(4):111-9, 2008.

GOMEZ-PINILLA, F; HILLMAN, C. The influence of exercise on cognitive abilities. Compr Physiol. Author manuscript; available in PMC Mar 13, 2014. doi: 10.1002/cphy.c110063

GUINEY, H., MACHADO, L. Benefits of regular aerobic exercise for executive functioning in healthy populations. Psychon. Bull. Rev. 20: 73-86, 2013.

HACKNEY, A.C. Exercise as a stressor to the human neuroendocrine system. Medicina (Kaunas);42(10):788-97, 2006.

HALE, L.A.; WATERS, D.; HERBISON, P. A randomized controlled trial to investigate the effects of water-based exercise to improve falls risk and physical function in older adults with lower extremity osteoarthritis. Archives of Physical Medicine and Rehabilitation, 93, 27- 34, 2012.

HARDY, C.J., REJESKI, W.J. Not what, but how one feels: The measurement of affect during exercise. J Sport Exerc Psychol, 11: 204-317, 1989.

HEANEY, J.L.J.; CARROLL, D.; PHILLIPS, A.C. DHEA, DHEA-S and cortisol responses to acute exercise in older adults in relation to exercise training status and sex. AGE; 35:395-405, 2013

HEDDEN, T., GABRIELI, J.D. Insights into the ageing mind: a view from cognitive neuroscience. Nat. Rev. Neurosci, 5: 87-96, 2004

IRIGARAY, T.Q.; GOMES FILHO, I.; SCHNEIDER, R.H. Efeitos de um treino de atenção, memória e funções executivas na cognição de idosos saudáveis. Psicol. Reflex. Crit. [online]. 2012, vol.25, n.1, pp. 182-187. ISSN 0102-7972.

IRVINE, A. B.; GELATT, V. A.; SEELEY, J.R.; MACFARLANE, P.; GAU, J. M. Web-based intervention to promote physical activity by sedentary older adults: Randomized controlled trial. Journal of Medical Internet Research, 15, e19, 2013.

JOHNSON AR, MILNER JJ, MAKOWSKI L: The inflammation highway: metabolism accelerates inflammatory traffic in obesity. Immunol Rev 249: 218-238, 2012.

KASHIHARA, K.; MARUYAMA, T.; MUROTA, M.; NAKAHARA, Y. Positive effects of acute and moderate physical exercise on cognitive function. J Physiol Anthropol.;28(4):155-64, 2009.

KAUSLER, D.H. Experimental psychology, cognition, and human aging. New York: Springer-Verlag. 1991

KOCHHAM, R.; VARELA, J. S.; LISBOA, C. S.; CHAVES, M. L. F. The mini mental state examination: review of cutoff ponits adjusted for schooling in a large southern brazilian sample. Dementia \& Neuropsychologia, 4, 35-41, 2010.

KRAEMER, W.J.; RATAMESS, N.A. Hormonal responses and adaptations to resistance exercise and training. Sports Med; 35(4):339-361, 2005.

KRUK, J. Physical Activity and Health. Asian Pacific Journal of Cancer Prevention. v.10, p. 721-728, 2009.

LAKS, J.; BAPTISTA, E.M.R.; CONTINO, A.L.B.; PAULA, E.O.; ENGELHARDT, E. Mini-mental state examination norms in a community-dwelling sample of elderly with low schooling in Brazil. Caderno de 
LEES, F.D.; CLARK, P.G.; NIGG, C.R.; NEWMAN, P. Barriers to exercise behavior among older adults: A focus group study. Journal of Aging and Physical Activity, 13, 23-33, 2005.

LENT, R. Neurociência da mente e do comportamento. RJ: Guanabara Koogan. 2008.

LOPES, R.P.; BARBOSA, A.S.; RAMOS, C.; ALMEIDA, W.R. O treinamento da dupla tarefa como proposta terapêutica para pacientes portadores da doença de Parkinson. NBC. Belo Horizonte, MG, v.03, n.06, dez. de 2013.

LOURENÇO, R. A.; VERAS, R. P.; RIBEIRO, P. C. C. Confiabilidade teste-reteste do mini-exame do estado mental em uma população idosa assistida em uma unidade ambulatorial de saúde. Revista Brasileira de Geriatria e Gerontologia, 11, 7-16, 2008.

LOURENÇO, R.A.; VERAS, R.P. Mini-Mental State Examination: psychometric characteristics in elderly outpatients. Revista de Saúde Pública, 40(4), 712-719, 2006.

LUPIEN, S.J.; DELEON, M.; DESANTI, S.; CONVIT, A.; TARSHISH, C.; NAIR N.P.V.; THAKUR, M.; MCEWEN, B.S.; HAUGER, R.L.; MEANEY, M.J.; Logitudinal increase in cortisol during human aging predicts hipocampal atrophy and memory deficits. Nature Neurisci, v. 1, pag 69-73, 1998.

LUPIEN, S.J.; MCEWEN, B.S. The acute effects of corticosteroids on cognition: integration of animal and human model studies. Brain Research Reviews, v.24, pag. 1-27, jun. 1997.

MAAIKE A, GEERT A, VERHAAR H, ALEMAN A, LUC V. Physical activity and enhanced fitness to improve cognitive function in older people without known cognitive impairment. Cochrane Database Syst Rev. 2008;2:1-37.

MARTINSON, B.; CRAIN, A.L.; PRONK, N.P.; O'CONNOR, P.J.; MACIOSEK, M.V. Changes in physical activity and short-term changes in health care changes: a prospective cohort study of older adults. Preventive Medicine, San Diego, v. 37, p. 319-326, 2003.

MATOS, MOREIRA e GUEDES, Aspectos Neuroendócrinos da Síndrome Metabólica. Arq Bras Endocrinol Metab. V. 47, n.4, 2003.

MATTHEWS, A.E.; LADITKA, S.B.; LADITKA, J.N.; WILCOX, S.; CORWIN, S.J.; LIU, R. Older adults perceived physical activity enablers and barriers: A multicultural perspective. Journal of Aging and Physical Activity, 18, 119- 140, 2010.

MAYEDA, E.R.; WHTIMER, R.A.; YAFFE, K. Diabetes and Cognition. Clin Geriatr Med; $31 ; 101-115$, 2015;

MEREGE FILHO, C.A.A.; ALVES, C.R.R.; SEPÚLVEDA, C.A.; COSTA, A.S.; LANCHA JUNIOR, A.H.; GUALANO, B. Influência do exercício físico na cognição: uma atualização sobre mecanismos fisiológicos. Rev Bras Med Esporte; Vol. 20, N o 3 - Mai/Jun, 2014.

MEYER, T.; SMEETS, T.; GIESBRECHT, T.; QUAEDFLIEG, C.W.; MERCKELBACH, H. Acute stress differentially affects spatial configuration learning in high and low cortisol-responding healthy adults. Eur. J. Psychotraumatol. 4:19854, 2013. doi: 10.3402/ejpt.v4i0.19854

MURDEN, R.A.; MCRAE, T.D.; KANER, S.; BUCKNAM, M.E. Mini-Mental State Exam scores vary with education in blacks and whites. J Am Geriatr Soc;; 39:149 -155, 1991.

NERI, M.C.; SOARES, W.L. Estimando o impacto da renda na saúde através de programas de transferência de renda aos idosos de baixa renda no Brasil. Cad. Saúde Pública, Rio de Janeiro, 
NIKOLAI, A.L.; NOVOTNY, B.A.; BOHNEN, C.L.; SCHLEIS, K.M.; DALLECK, L.C. Cardiovascular and metabolic responses to water aerobics exercise in middle-aged and older adults. Journal of Physical Activity and Health, 6, 333-338, 2009.

NITRINI, R.; LEFEVRE, B.H.; MATHIAS, S.C.; CARAMELLI, P.; CARRILHO, P.E.M.; SAUAIA, N.; MASSAD, E.; TAKIGUTI, C.; SILVA, I.O.; PORTO, C.S.; MAGILA, M.C.; SCAFF, M. Testes Neurológicos de aplicação simples para o diagnóstico de demência. Arq. Neuropsiquiatr.52 (4), 457465, 1994.

NUNES, A. O envelhecimento populacional e as despesas do sistema único de saúde. In CAMARANO, A A (org.). Os novos idosos brasileiros: muito além dos 60? Rio de Janeiro, IPEA, p. 427-450, 2004.

O'SHEA, S.; MORRIS, M.E.; IANSEK, R.; Dual task interference during gait in people with Parkinson disease: effects of motor versus cognitive secondary tasks. Phys Ther, 82:888-97, 2002.

PATEL, P.; LAMAR, M.; BHATT, T. Effect of type of cognitive task and walking speed on cognitivemotor interference during dual-task walking. Neurocience. Volume 260, 28 February, Pages 140-148, 2014.

PAULI, R.; SOUZA, L.; ROGATTO, G.; GOMES, R.; LUCIANO, E. Glicocorticóides e síndrome metabólica: aspectos favoráveis do exercício físico nesta patofisiologia. Rev Port Cien Desp; 6:217228, 2006.

PEREIRA, A.; FREITASA, C.; MENDONÇA, C.; MARÇALA, F.; SOUZA, J.; NORONHA, J.P.; LESSA, L.; MELOA, L.; GONÇALVES, R.; SHOLL-FRANCOB, C. Envelhecimento, estresse e sociedade: uma visão psiconeuroendocrinológica. Cien Cong 1:34-53, 2004.

PESCE, C., CROVA, C., CEREATTI, L., CASELLA, R., \& BELLUCCI, M. Physical activity and mental performance in preadolescents: Effects of acute exercise on free-recall memory. Mental Health and Physical Activity, 2(1), 2009, 16-22.

PIAZZA, J.R.; CHARLES, S.T.; STAWSKI, R.S.; ALMEIDA, D.M. Age and the association between negative affective states and diurnal cortisol. Psychology and Aging, vol.28(1), 47-56, 2013.

PLASSMAN BL, WILLIAMS J, BURKE JR, HOLSINGER T, BENJAMIN S. Systematic review: factors associated with risk for and possible prevention of cognitive decline in later life. Ann Intern Med. 2010; 153:182-193.

PRATT, M.; MACERA, C.A.; WANG, G. Higher direct medical costs associated with physical inactivity. Physician Sportsmed. v.28, n. 10, p. 63-70, 2000.

REYNOLDS, R.M.; STRACHAN, M.W.J.; LABAD, J.; LEE, A. J.; FRIER, B.M.; FOWKES, F.G. Morning cortisol levels and cognitive abilities in people with type 2 diabetes the edinburgh type 2 diabetes study. Diabetes Care 33, 714-720, 2010. doi: 10.2337/dc09-1796

RHYU, I.J.; BYTHEWAY, J.A.; KOHLER, S.J.; LANGE, H.; LEE, K.J.; BOKLEWSKI, J. Effects of aerobic exercise training on cognitive function and cortical vascularity in monkeys. Neuroscience;2 ;167(4):1239-48, 2010.

ROSA NETO, F.; SAKAE, T. M.; POETA, L. S. Validação dos parâmetros motores na terceira idade. Revista Brasileira de Ciência e Movimento, v.19, n.1, pp. 20-25, 2010.

RUSCHEWEYH, R.; WILLEMER, C.; KRUGER, K.; DUNING, T.; WARNECKE, T.; SOMMER, J.; VOLKER, K.; HO, H.V.; MOOREN, F.; KNECHT, S.; FLOEL, A. Physical activity and memory functions: 
SALTHOUSE, T.A. Mediation of adult age differences in cognition by reductions in working memory and speed of processing. Psychological Science, 2, 179-183, 1991.

SCHLOSSER, N.; WOLF, O.T.; FERNANDO, S.C.; TERFEHR, K.; OTTE, C.; SPITZER, C. Effects of acute cortisol administration on response inhibition in patients with major depression and healthy controls. Psychiatry Res. 209, 439-446, 2013. doi: 10.1016/j.psychres.2012.12.019

SCHUTZER, K.A.; GRAVES, B.S. Barriers and motivations to exercise in older adults. Preventative Medicine, 39, 1056-1061, 2004.

SCHWABE, L.; JOËLS, M.; ROOZENDAAL, B.; WOLF, O.T.; OITZL, M. S. Stress effects on memory: an update and integration. Neurosci. Biobehav. Rev. 36, 1740-1749, 2012. doi: 10.1016/j. neubiorev.2011.07.002

SHUCH, F.B.; PINTO, S.S.; BAGATINI, N.C.; ZAFFARI, P.; ALBERTON, C.L.; CADORE, E.L.; SILVA, R.F.; KRUEL, L.F.M. Water-Based Exercise and Quality of life in Women: the role of depressive symptoms. Women Health. 54(2):161-75, 2014.

SILVA FILHO, J.R.; FERNANDES, J.R.P.; LOBO DA COSTA, P.H. Estudo comparativo entre corrida em esteira e a corrida aquática em duas profundidades diferentes. Rev. bras. Educ. Fís. Esp., São Paulo, v.19, n.3, p.243-54, jul./set. 2005.

SILVA, J.C.S, BRASIL. Ministério da Saúde. Coordenação de Doenças Crônico Degenerativas. Orientações básicas sobre atividade física e saúde para profissionais das áreas de educação e saúde, 1995.

SMITH PJ, BLUMENTHAL JA, HOFFMAN BM, COOPER H, STRAUMAN TA, WELSH-BOHMER K, BROWNDYKE JN, SHERWOOD A. Aerobic exercise and neurocognitive performance: A meta-analytic review of randomized controlled trials. Psychosom Med. 2010;72:239-252.

SPIRDUSO WW, Clifford P. Replication of age and physical activity effects on reaction and movement time. J Gerontol. 1978;33:26-30.

STRANAHAN, A.M.; LEE, K.; MATTSON, M.P. Central mechanisms of HPA axis regulation by voluntary exercise. Neuromolecular Med; 10(2):118-27, 2008.

STUART-HAMILTON, I. Psicologia del envejecimento. Madrid: Morata, 2002.

TAHERI, M.; IRANDOUST, K. The effects of water-based exercises on depressive sympotoms and nonspecific low back pain in retired professional athletes: a randomized controlled trial. International Journal of Sport Studies. Vol., 4 (4), 434-440, 2014.

THOMAS, J. R; NELSON, J. K. Métodos de pesquisa em atividade física. 3. ed. Porto Alegre: Artmed, 2002.

TOMPOROWSKI, P.D. Effects of acute bouts of exercise on cognition. Acta Psychol (Amst).;112 (3):297-324, 2003.

TRAUSTADÓTTIR, T.; BOSCH, P.R.; MATT, K.S. The HPA axis response to stress in women: effects of aging and fitness. Psychoneuroendocrinology;30(4):392-402, 2005.

TSATSOULIS, A.; FOUNTOULAKIS, S. The protective role of exercise on stress system dysregulation and comorbidities. Ann N Y Acad Sci;1083:196-213, 2006. 
VALE, R.G.S.; OLIVEIRA, R.D.; PERNAMBUCO, C.S.; MENESES, Y.P.S.F.M.; NOVAES, J.S.; ANDRADE, A.F.D. Effects of muscle strength and aerobic training on basal serum levels of IGF-1 and cortisol in elderly women. Arch Gerontol Geriat 49:343-347, 2009.

VAN AST, V.A.; CORNELISSE, S.; MEETER, M.; JOËLS, M.; KINDT, M. Timedependent effects of cortisol on the contextualization of emotional memories. Biol. Psychiatry; 74, 809-816, 2013. doi: 10.1016/j.biopsych.2013.06.022

VAN PRAAG, H.; KEMPERMANN, G.; GAGE, F.H. Running increases cell proliferation and neurogenesis in the adult mouse dentate gyrus. Nat. Neurosci., 2 (1999), pp. 266-270

VARGAS, L.S.; LARA, M.V.S.; MELLO-CAPES, P.B. Influência da diabetes e a prática de exercício físico e atividades cognitivas e recreativas sobre a função cognitiva e emotividade em grupos de terceira idade. Rev. bras. geriatr. gerontol. vol.17 no.4 Rio de Janeiro Oct./Dec. 2014.

VAYNMAN, S.S.; YING, Z.; YIN, D.; GOMEZ-PINILLA, F. Exercise differentially regulates synaptic proteins associated to the function of BDNF. Brain Res., 1070 (2006), pp. 124-130.

VIEIRA, S. Introdução à Bioestatística. 3.ed. Rio de Janeiro: Campus, 1980.

WANG, T.; BELZA, B.; THOMPSON, F.E.; WHITNEY, J.D.; BENNETT, K. Effects of aquatic exercise on flexibility, strength, and aerobic fitness in adults with osteoarthritis of the hip or knee. Journal of Advanced Nursing, 57, 141- 152, 2007.

WANG, T.; BELZA, B.; THOMPSON, F.E.; WHITNEY, J.D.; BENNETT, K. Effects of aquatic exercise on flexibility, strength, and aerobic fitness in adults with osteoarthritis of the hip or knee. Journal of Advanced Nursing, 57, 141- 152, 2007.

WEISS, J.P.; FROELICHER, V.F.; MYERS, J.N.; HEIDENREICH, P.A. Health-Care Costs and Exercise Capacity. Chest, v.126, p. 608-613, 2004.

WILCOX, S.; SHARKEY, J.R.; MATHEWS, A.E.; LADITKA, J.N.; LADITKA, S.B.; LOGSDON, R.G. Perceptions and beliefs about the role of physical activity on brain health in older adults. The Gerontologist, 49, S61-S71, 2009.

WINTER, B.; BREITENSTEIN, C.; MOOREN, F.C.; VOELKER, K.; FOBKER, M.; LECHTERMANN, A.; KRUEGER, K.; FROMME, A.; KORSUKEWITZ, C.; FLOEL, A.; KNECHT, S. High impact running improves learning. Neurobiol. Learn Mem., 87 (2007), pp. 597-609.

WORLD MEDICAL ASSOCIATION: Declaration of Helsinki. JAMA 277:925- 926, 1997.

YANAGISAWA, H.; DAN, I.; TSUZUKI, D.; KATO, M.; OKAMOTO, M.; KYUTOKU, Y.; Acute moderate exercise elicits increased dorsolateral prefrontal activation and improves cognitive performance with Stroop test. Neuroimage; 1; 50(4):1702-10, 2010.

YASSUDA, M.S.; BATISTONI, S.S.T.; FORTES, A.G.; NERI, A.L. Treino de memória no idoso saudável: benefícios e mecanismos. Psicologia Reflexão e Crítica, 19, 470-481. 2006. 


\section{ANEXO A}

\section{Mini Exame de Estado Mental (MEEM)}

Teste de rastreamento e avaliação rápida da função cognitiva Descrição

É o teste mais utilizado para avaliar a função cognitiva por ser rápido (em torno de 10 minutos), de fácil aplicação, não requerendo material específico. Deve ser utilizado como instrumento de rastreamento não substituindo uma avaliação mais detalhada, pois, apesar de avaliar vários domínios (orientação espacial, temporal, memória imediata e de evocação, cálculo, linguagem-nomeação, repetição, compreensão, escrita e cópia de desenho), não serve como teste diagnóstico, mas sim pra indicar funções que precisam ser investigadas. É um dos poucos testes validados e adaptados para a população brasileira.

1. Orientação espacial ( $0-5$ pontos)

Em que dia estamos?
( ) Ano
( ) Semestre
( ) Mês
( ) Dia
( ) Dia da Semana

2. Orientação espacial ( $0-5$ pontos)

Onde Estamos?
( ) Estado
( ) Cidade
( ) Bairro
( ) Rua
( ) Local

3. Repita as palavras ( $0-3$ pontos $)$
( ) Caneca
( ) Tijolo
( ) Tapete

4. Cálculo ( $0-5$ pontos)

O senhor faz cálculos?

Sim (vá para a pergunta 4a)

Não (vá para a pergunta $4 b$ )

4a. Se de 100 fossem tirados 7 quanto restaria? E se tirarmos mais 7 ?
( ) 93
( ) 86
( ) 79
( ) 72
( ) 65

4b. Soletre a palavra MUNDO de trás pra frente:
( ) $\mathrm{O}$
( ) D
( ) $\mathrm{N}$
( ) U
( ) M

5. Memorização (0 -3 pontos)

Peça para o entrevistado repetir as palavras ditas há pouco.
( ) Caneca
( ) Tijolo
( ) Tapete

6. Linguagem $(0-2)$ pontos

Mostre um relógio e uma caneta e peça para o entrevistado nomeá-los.
( ) Relógio
( ) Caneta

7. Linguagem (1 ponto)

Solicite ao entrevistado que repita a frase:

( ) NEM AQUI, NEM ALI, NEM LÁ.

8. Linguagem (0 - 3 pontos)

Siga uma ordem de 3 estágios. 
( ) Pegue esse papel com a mão direita chão

9. Linguagem (1 ponto)

( ) Escreva em um papel: "FECHE OS OLHOS". Peça para o entrevistado ler a ordem e excutá-la.

10. Linguagem (1 ponto)

( ) Peça para o entrevistado escrever uma frase completa. A frase deve ter um sujeito e um objeto e deve ter sentido. Ignore a ortografia.

11. Linguagem (1 ponto)

( ) Peça ao entrevistado para copiar o seguinte desenho. Verifique se todos estão preservados e se os lados da intersecção formam um quadrilátero. Tremor e rotação podem ser ignorados.

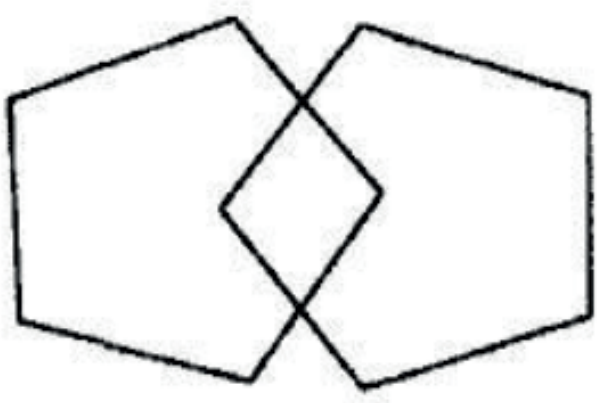



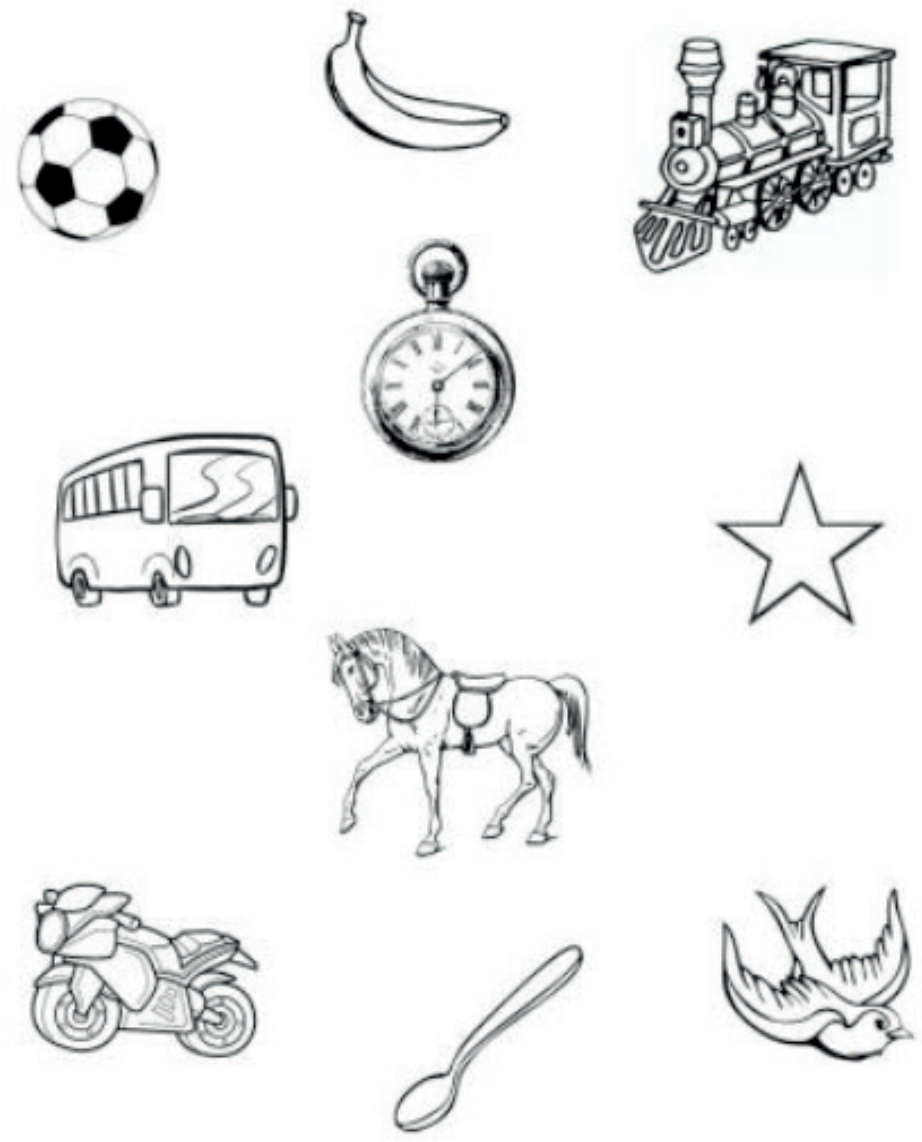

Grupo de imagem 01 (Nitrine et al., 1994 adaptado por Silva, 2014) 


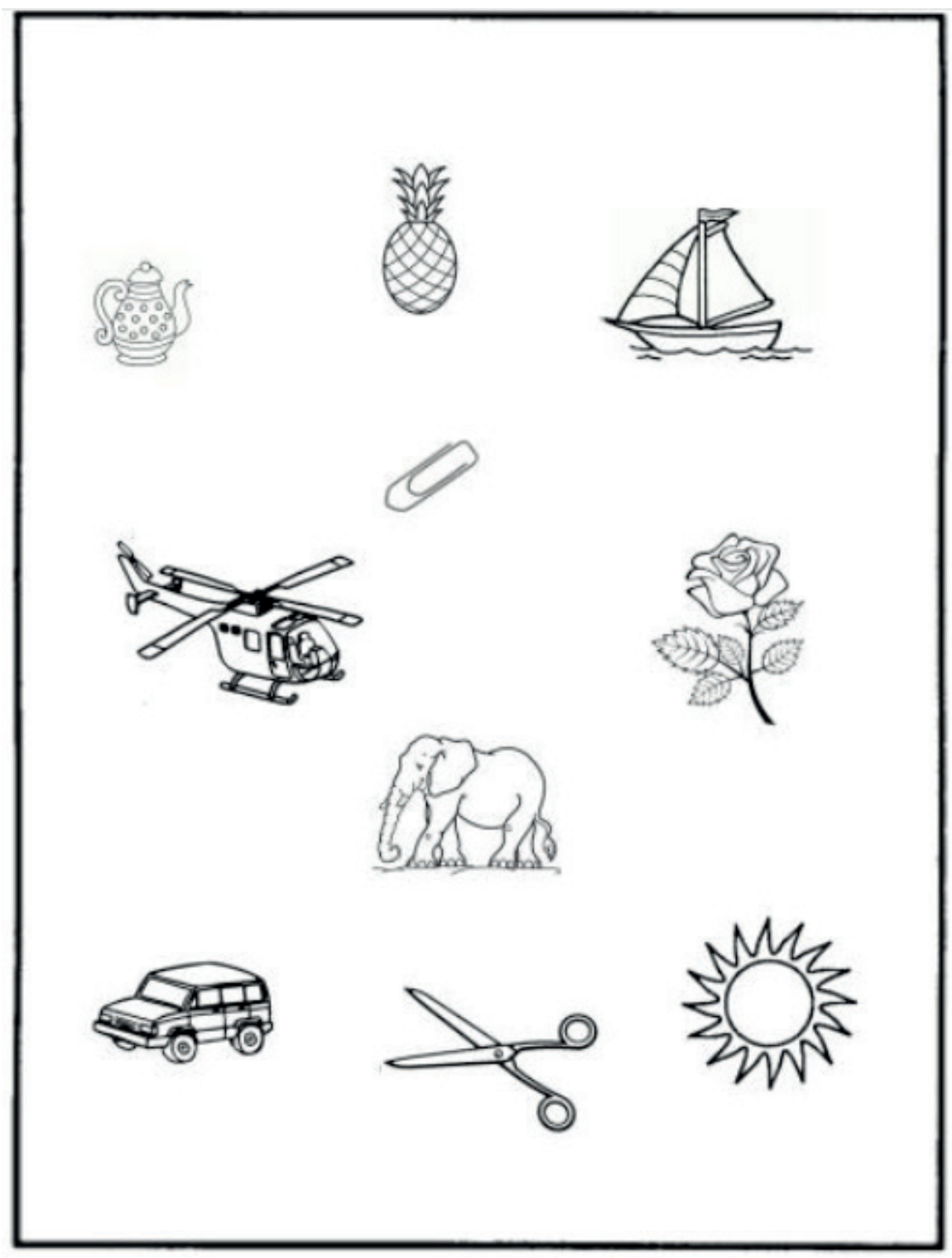

Grupo de imagem 02 (Nitrine et al., 1994 adaptado por Silva, 2014) 


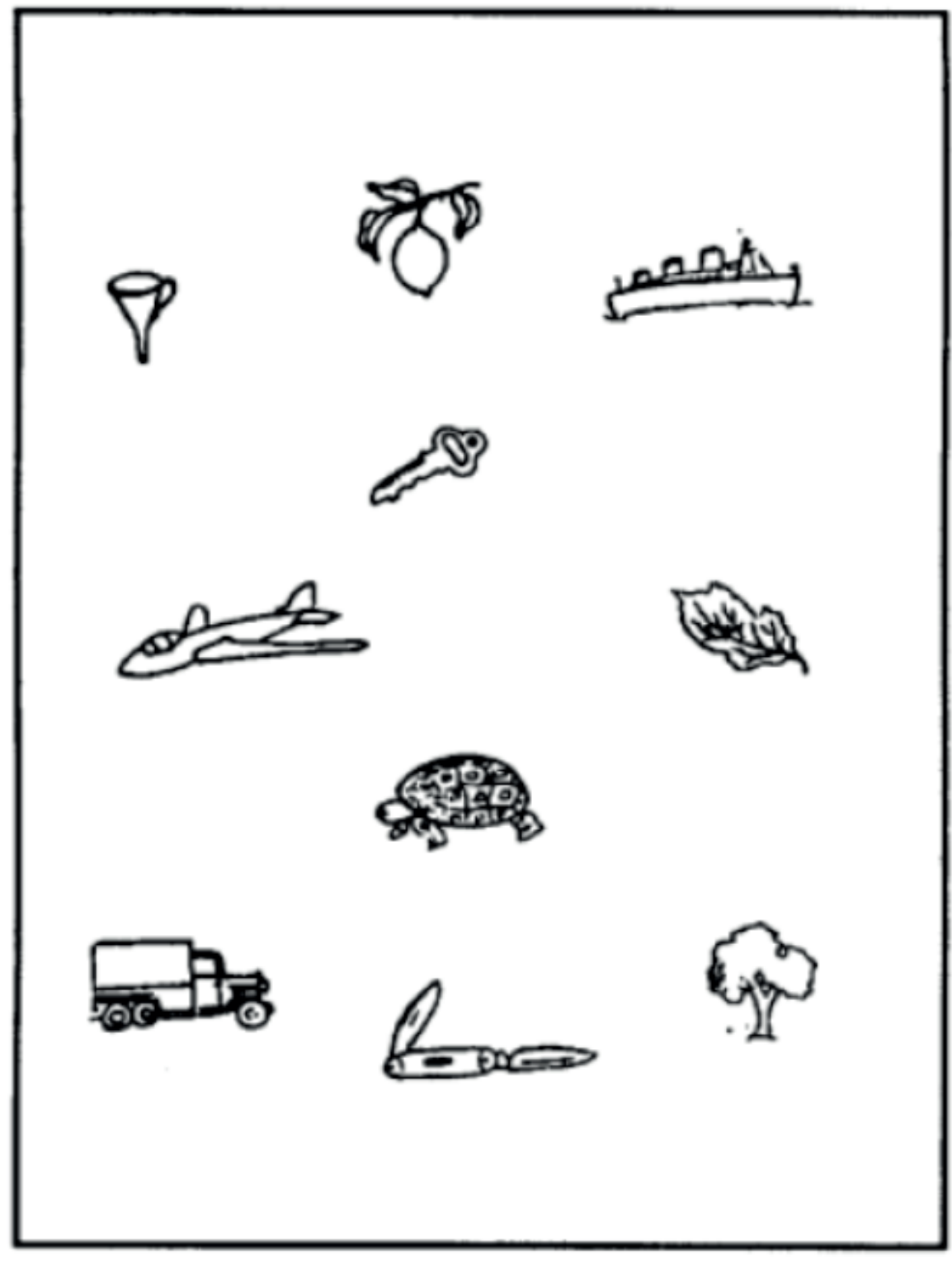

Grupo de imagem 03 (Nitrine et al., 1994) 


\section{UNIVERSIDADE FEDERAL DO RIO GRANDE DO NORTE / UFRN CAMPUS CENTRAL}

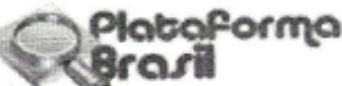

\section{PARECER CONSUBSTANCIADO DO CEP}

\section{DADOS DO PROJETO DE PESQUISA}

Titulo da Pesquisa: EFEITOS DE PRAXIAS IDEOMOTORAS NA QUANTIFICAÇÃO SÉRICA DO BDNF E SUA RELAÇÃO COM A MEMÓRIA NO PROCESSO DE ENVELHECIMENTO

Pesquisador: HUDDAY MENDES DA SILVA

Área Temática:

Versão: 2

CAAE: 28522114.7 .0000 .5537

Instituição Proponente: Universidade Federal do Rio Grande do Norte - UFRN

Patrocinador Principal: Financiamento Próprio

\section{DADOS DO PARECER}

Número do Parecer: 719.271

Data da Relatoria: $30 / 05 / 2014$

\section{Apresentação do Projeto:}

Pesquisa caracterizada como estudo transversal, com uma amostra de 40 participantes fisicamente ativos, com faixa etárias acima dos 50 anos. Esses serão recrutados dentre os que frequentam o Programa de Extensåo "Caminhada na água" do Departamento de Educação Física. Critérios de inclusăo e de exclusăo foram estabelecidos. Para a coleta de dados serão aplicados primeiramente o MEEM (Mini Exame do Estado Mental) para avaliar o estado cognitivo geral, que servirá como critério de inclusāo da pesquisa, assim como a cartela de Optótipos, no qual verifica a acuidade visual. Depois, será empregada a Escala Motora para Terceira Idade, também empregada como critério de inclusăo. Para verificaçăo da memória será utilizado o Teste de Memória (memorização de 10 figuras identificadas, com avaliação da memória imediata com pré-estimulo, pós-estímulo e após 48 horas depois da intervenção. O Fator Neurotrófico Derivado do Cérebro (BDNF) sérico será coletado a partir de $5 \mathrm{ml}$ de sangue, em jejum e encaminhado ao departamento de fisiologia da UFRN para a análise. Em seguida ocorrerá a distribuiçăo da amostra em dois grupos (Grupo Marcha Automática - GMA e Grupo Marcha Praxica - GMP) possibilitando a comparação para os diferentes programas, contando com um total de 16 semanas de intervenção. A análise dos resultados dar-se-á pela aplicaçăo do teste de normalidade de Shapiro-Wilk e do test t pareado para verificaçăo entre os grupos (paramétricos) ou test de Mann-Whitney, caso demonstrado uma distribuição năo

Endereço: Av. Senador Salgado Filho, 3000

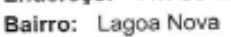




\section{UNIVERSIDADE FEDERAL DO RIO GRANDE DO NORTE / UFRN CAMPUS CENTRAL}

Continuação do Parecer: 719.271

normal, será ainda utilizado uma análise de variåncia a ANOVA one-way (paramétricos) ou o teste de Kruskal-Wallis, para identificaçăo de possiveis diferenças entre os grupos e as variáveis dependentes. Para verificação de uma possivel relação entre e associação entre a memória visual e as mudanças dos resultados do BDNF sérico, utilizar-se-á do teste de correlaçăo de Pearson (paramétrico) ou Sperman (nāoparamétrico), visando um nível de significância de $p<0,05$.

\section{Objetivo da Pesquisa:}

Objetivo Primário:

Verificar a relação entre os niveis séricos do BDNF com o desempenho de memória no processo de envelhecimento em sujeitos que desenvolvem atividade práxicas e automáticas.

Objetivos Secundários:

1. Verificar a diferença entre os grupos (GMA e GMP) quanto aos niveis séricos do BDNF e o desempenho de memória;

2. Correlacionar os niveis séricos do BDNF com o desempenho de memória em sujeitos praticantes de atividade fisica automática e práxica.

\section{Avaliação dos Riscos e Benefícios:}

A previsão de riscos é classificada como baixa, ou seja, é semelhante ou menor ao vivenciado na atividade física diária. Pode ocorrer desconforto durante a coleta de $05 \mathrm{ml}$ de sangue para dosagem do BDNF sérico numa primeira etapa e mais $05 \mathrm{ml}$ numa segunda etapa.

Como benefícios são citados que o participante será informado acerca de sua memória declarativa de curto prazo, acuidade visual e aspectos motores e terá a possibilidade de verificar quanto a atividade fisica poderá favorecer sua memória.

\section{Comentários e Consideraçōes sobre a Pesquisa:}

A pesquisa pode gerar dados sobre os beneficios da praxia ideomotora como intervenção não invasiva para possiveis problemas de memórias declarativas aumentando o acervo de tratamentos para doenças como Alzheimer e Parkinson.

\section{Consideraçōes sobre os Termos de apresentação obrigatória:}

Todos os termos de apresentação obrigatória para essa pesquisa foram apresentados.

Endereço: Av. Senador Salgado Filho, 3000

Bairro: Lagoa Nova

UF: RN Municipio: NATAL

Telefone: (84)3215-3135 Fax: (84)3215-3135 E-mail: cepufm@reitoria.ufrn.br 


\section{UNIVERSIDADE FEDERAL DO RIO GRANDE DO NORTE I UFRN CAMPUS CENTRAL}

Continuaçăo do Parecer: 719.271

\section{Recomendações:}

Recomendamos ao pesquisador que no Termo de Consentimento Livre e Esclarecido - TCLE a assinatura do participante e a assinatura do pesquisador fiquem na mesma folha. Isto é uma exigência da Res. 466/12 do Conselho Nacional de Saúde - CNS.

\section{Conclusōes ou Pendências e Lista de Inadequaçōes:}

Após a revisão ética das respostas às pendências levantadas no parecer anterior, concluímos que as mesmas foram reparadas adequadamente.

Essa adequação situa o protocolo em questão dentro dos preceitos básicos da ética nas pesquisas que envolvem o ser humano.

\section{Situação do Parecer:}

Aprovado

\section{Necessita Apreciação da CONEP:}

Nåo

\section{Considerações Finais a critério do CEP:}

Em conformidade com a Resoluçăo 466/12 do Conselho Nacional de Saúde - CNS e Manual Operacional para Comitês de Ética - CONEP é da responsabilidade do pesquisador responsável:

1. elaborar o Termo de Consentimento Livre e Esclarecido - TCLE em duas vias, rubricadas em todas as suas páginas e assinadas, ao seu término, pelo convidado a participar da pesquisa, ou por seu representante legal, assim como pelo pesquisador responsável, ou pela (s) pessoa (s) por ele delegada(s), devendo as páginas de assinatura estar na mesma folha (Res. 466/12 - CNS, item IV.5d);

2. desenvolver o projeto conforme o delineado (Res. 466/12 - CNS, item XI.2c);

3. apresentar ao CEP eventuais emendas ou extensōes com justificativa (Manual Operacional para Comitês de Ética - CONEP, Brasilia - 2007, p. 41);

4. descontinuar o estudo somente após análise e manifestação, por parte do Sistema CEP/CONEP/CNS/MS que o aprovou, das razōes dessa descontinuidade, a não ser em casos de justificada urgência em beneficio de seus participantes (Res. 446/12 - CNS, item III.2u);

5. elaborar e apresentar os relatórios parciais e finais (Res. 446/12 - CNS, item XI.2d);

6. manter os dados da pesquisa em arquivo, físico ou digital, sob sua guarda e responsabilidade, por um período de 5 anos após o término da pesquisa (Res. 446/12 - CNS, item XI.2f);

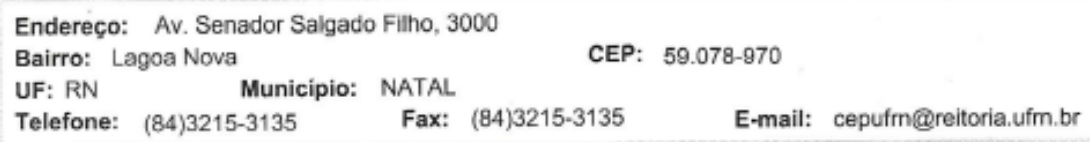




\section{UNIVERSIDADE FEDERAL DO \\ RIO GRANDE DO NORTE / UFRN CAMPUS CENTRAL}

Continuaçào do Parecer: 719.271

7. encaminhar os resultados da pesquisa para publicação, com os devidos créditos aos pesquisadores associados e ao pessoal técnico integrante do projeto (Res. 446/12 - CNS, item XI.2g) e,

8. justificar fundamentadamente, perante o CEP ou a CONEP, interrupção do projeto ou não publicação dos resultados (Res. 446/12 - CNS, item XI.2h).

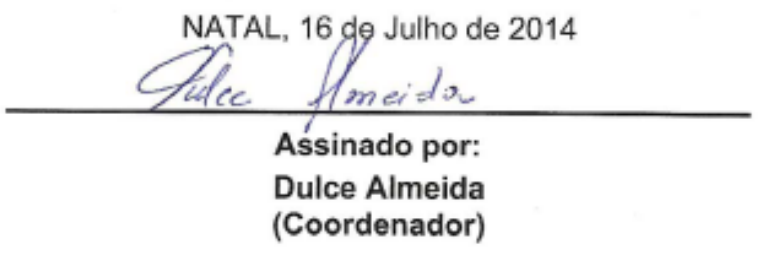

Endereço: Av. Senador Salgado Filho, 3000

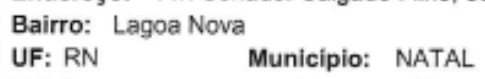

Telefone: (84)3215-3135 Fax: (84)3215-3135 E-mail: cepufm@reitoria.ufm.br 


\section{APÊNDICE A}

Movimentos de Estimulação motora (Estimulação Práxica)

Sequência de 30 movimentos translatórios combinados com rotações articulares para exercício de habilidades motoras locomotoras sob controle motor práxico em meio aquático

\begin{tabular}{|c|c|c|c|}
\hline FRENTE & TRÁS & GIRO OU LATERAL & $\begin{array}{l}\text { GIRO OU } \\
\text { CONTRALATERAL }\end{array}$ \\
\hline $\begin{array}{l}\text { 1- Sobrepasso com } \\
\text { flexão do quadril e } \\
\text { joelho alternados }\end{array}$ & $\begin{array}{l}\text { 2- Sobrepasso com } \\
\text { flexão do quadril e joelho } \\
\text { alternados }\end{array}$ & $\begin{array}{l}\text { 3- Sobrepasso com } \\
\text { abdução do quadril } \\
\text { e flexão do joelho } \\
\text { alternados }\end{array}$ & \\
\hline $\begin{array}{l}\text { 4- Flexão de quadril } \\
\text { alternada }\end{array}$ & $\begin{array}{l}\text { 5- Extensão de quadril } \\
\text { alternada }\end{array}$ & $\begin{array}{l}\text { 6- Abdução de quadril } \\
\text { com a direita }\end{array}$ & $\begin{array}{l}\text { 7- Abdução de quadril } \\
\text { com a esquerda }\end{array}$ \\
\hline $\begin{array}{l}\text { 8- Circundação sentido } \\
\text { flexão/abdução }\end{array}$ & $\begin{array}{l}\text { 9- Circundação sentido } \\
\text { extensão/abdução }\end{array}$ & $\begin{array}{l}\text { 10- Circundação sentido } \\
\text { flexão/abdução com } \\
\text { direita }\end{array}$ & $\begin{array}{l}\text { 11- Circundação } \\
\text { sentido flexão/ } \\
\text { abdução com a } \\
\text { esquerda }\end{array}$ \\
\hline 12- Mae gueri & 13- Ushiro gueri & $\begin{array}{l}\text { 14- Chute lateral com a } \\
\text { direita }\end{array}$ & $\begin{array}{l}\text { 15- Chute lateral com } \\
\text { a esquerda }\end{array}$ \\
\hline $\begin{array}{l}\text { 16- Sobrepasso com } \\
\text { circundação sentido } \\
\text { adução/flexão alternado }\end{array}$ & $\begin{array}{l}\text { 17- Sobrepasso com } \\
\text { circundação sentido } \\
\text { adução/flexão alternado }\end{array}$ & $\begin{array}{l}\text { 18- Sobrepasso com } \\
\text { circundação sentido } \\
\text { abdução/flexão com a } \\
\text { direita }\end{array}$ & $\begin{array}{l}\text { 19- Sobrepasso com } \\
\text { circundação sentido } \\
\text { abdução/flexão com a } \\
\text { esquerda }\end{array}$ \\
\hline $\begin{array}{l}\text { 20- Passo com } \\
\text { elevação de joelho } \\
\text { direito com saltito com } \\
\text { esquerda à frente }\end{array}$ & $\begin{array}{l}\text { 21- Passo com elevação } \\
\text { de joelho esquerdo com } \\
\text { saltito com direita à frente }\end{array}$ & $\begin{array}{l}\text { 22- Extensão do quadril } \\
\text { com meio giro para trás } \\
\text { alternado }\end{array}$ & $\begin{array}{l}\text { 23- Flexão do com } \\
\text { meio giro para frente } \\
\text { alternado }\end{array}$ \\
\hline $\begin{array}{l}\text { 24- Passo a frente com } \\
\text { circundução do quadril } \\
\text { sentido frente lateral } \\
\text { alternado }\end{array}$ & $\begin{array}{l}\text { 25- Passo atrás com } \\
\text { circundução do quadril } \\
\text { sentido lateral trás } \\
\text { alternado }\end{array}$ & $\begin{array}{l}\text { 26- Passo lateral com } \\
\text { circundução do quadril } \\
\text { sentido trás lateral com } \\
\text { direita }\end{array}$ & $\begin{array}{l}\text { 27- Passo lateral com } \\
\text { circundução do quadril } \\
\text { sentido trás lateral } \\
\text { com esquerda }\end{array}$ \\
\hline $\begin{array}{l}\text { 28- Faça um } \\
\text { movimento diferente } \\
\text { para frente }\end{array}$ & $\begin{array}{l}\text { 29- Faça um movimento } \\
\text { diferente para trás }\end{array}$ & $\begin{array}{l}\text { 30- Faça um } \\
\text { deslocamento em sentido } \\
\text { diferente na piscina }\end{array}$ & \\
\hline
\end{tabular}




\section{APÊNDICE B}

\section{TERMO DE CONSENTIMENTO LIVRE E ESCLARECIDO - TCLE}

\section{Esclarecimentos}

Este é um convite para você participar da pesquisa: Efeitos de praxias ideomotoras na quantificação sérica do fator neurotrófico derivado do cérebro e sua relação com a memória no processo de envelhecimento, que tem como pesquisador responsável Prof. Hudday Mendes da Silva.

Esta pesquisa pretende analisar o efeito da caminhada com exercícios combinados (praxias) em relação ao desempenho da memória e os níveis séricos dos fatores neurotróficos derivados do cérebro.

O motivo que nos leva a realizar este estudo é a necessidade de contribuir para uma maior participação de idosos em programas de exercícios físicos, visto que o envelhecimento naturalmente apresenta uma diminuição de que fatores cognitivos, como a memória, podendo ao passar do tempo essas pessoas virem a ter dependências de terceiros para realização de atividades do dia-a-dia, tal como, ir ao mercado, ir à igreja sozinho, lembrar nomes de pessoas, números de telefones e até mesmo endereços, entre outros.

Caso o(a) senhor(a) opte em participar, deverá comparecer ao Laboratório de Atividade Física e Saúde (LAFIS) do Departamento em Educação Física da Universidade Federal do Rio Grande do Norte (UFRN) por 3 dias intercalados com intervalo de 24 horas aproximadamente (Segunda, quarta e sexta feira) para realização das avaliações, sendo que o tempo de cada dia irá durar por volta de 1 hora.

No $1^{\circ}$ dia (segunda-feira), o(a) senhor(a) realizará o preenchimentos da anamnese, teste de optotipos "E" (verificar a acuidade visual) e o Teste de Escala Motora para Terceira Idade (EMTI), caso sinta-se constrangido com alguma das perguntas apresentadas, pode não responde-las.

No $2^{\circ}$ dia (quarta-feira), o(a) senhor(a) realizará antes da caminhada o teste de Memória composto por um questionário contendo 10 imagens e coleta de sangue $(5 \mathrm{ml})$. $\mathrm{O}$ sangue coletado será armazenado e levado para o laboratório de fisiologia do Universidade Federal do Rio Grande do Norte, onde o mesmo será analisado. Logo em seguida, realizará o exercício de caminhada na água de 30 minutos com ou sem movimentos combinados, isso irá depender em qual dos grupos irá ser sorteado em participar. Na sequência realizará novamente o teste de memória e a coleta sanguínea $(5 \mathrm{ml})$.

No $3^{\circ}$ dia (sexta-feira), o(a) senhor(a) realizará novamente o teste de memória e a coleta sanguínea $(5 \mathrm{ml})$ para verificar o efeito tardio da caminhada na água.

Durante a realização dos testes a previsão de risco é baixa, ou seja, o risco que o(a) senhor(a) corre é semelhante ao vivenciado na atividade física diária que já é realizada no programa de exercício físico proposto pelo Laboratório de Atividade Física e Saúde no qual já participa, sendo assim, não há nenhuma previsão de riscos adicionais não mencionados 
nesse termo.

Pode acontecer um desconforto durante a coleta sanguínea, o(a) senhor(a) sentirá uma leve picada ao ser penetrado a agulha no seu braço, que será minimizado logo após a retirada de $5 \mathrm{ml}$ de sangue, proporcionando assim o senhor obter a informação de como está o nível sérico do BDNF antes e após o exercício, dessa forma podendo esclarecer o quanto está sendo estimulado essa produção.

$\mathrm{O}(\mathrm{A})$ senhor(a) terá como benefício, conhecer seus aspectos motores, sua acuidade visual e como está o desempenho de sua memória antes e após a prática de atividade física. Além disso, contribuirá para o entendimento científico do efeito da atividade física sobre o desempenho da memória e na neurogênese em sujeitos em envelhecimento como também possibilidades de tratamentos de doenças como o Parkinson e Alzheimer.

Em caso de algum problema que o(a) senhor(a) possa ter, relacionado com a pesquisa, terá o direito a assistência gratuita do serviço médico (pública ou privada) e em todo momento será acompanhado(a) pelo Prof. Hudday Mendes da Silva e pesquisadores auxiliares.

Durante todo o período da pesquisa o(a) senhor(a) poderá tirar suas dúvidas ligando para o Prof. Hudday Mendes da Silva nos números: (84) 9600.4806 e/ou (88) 9624.7982.

$\mathrm{O}$ o(a) senhor(a) tem o direito de se recusar a participar ou retirar seu consentimento, em qualquer fase da pesquisa, sem nenhum prejuízo para o(a) senhor(a).

Os dados que o(a) senhor(a) irá nos fornecer serão confidenciais e serão divulgados apenas em congressos ou publicações científicas, não havendo divulgação de nenhum dado que possa lhe identificar.

Esses dados serão guardados pelo pesquisador responsável por essa pesquisa em local segura e por um período de 5 anos.

Se o(a) senhor(a) tiver algum gasto pela sua participação nessa pesquisa, ele será assumido pelo pesquisador e reembolsado para o(a) senhor(a).

Se o(a) senhor(a) sofrer algum dano comprovadamente decorrente desta pesquisa, o(a) senhor(a) será indenizado.

Qualquer dúvida sobre a ética dessa pesquisa o(a) senhor(a) deverá ligar para o Comitê de Ética em Pesquisa da Universidade Federal do Rio Grande do Norte, telefone (84) 3215-3135.

Este documento foi impresso em duas vias. Uma ficará com você e a outra com o pesquisador responsável (Prof. Hudday Mendes da Silva). 
Após ter sido esclarecido sobre os objetivos, importância e o modo como os dados serão coletados nessa pesquisa, além de conhecer os riscos, desconfortos e benefícios que ela trará para mim e ter ficado ciente de todos os meus direitos, concordo em participar da pesquisa EFEITOS DE PRAXIAS IDEOMOTORAS NA QUANTIFICAÇÃO SÉRICA DO FATOR NEUROTRÓFICO DERIVADO DO CÉREBRO E SUA RELAÇÃO COM A MEMÓRIA NO PROCESSO DE ENVELHECIMENTO, e autorizo a divulgação das informações por mim fornecidas em congressos e/ou publicações científicas desde que nenhum dado possa me identificar.

Natal de de

Assinatura do participante da pesquisa

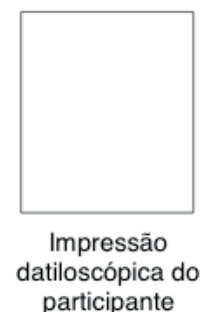

Declaração do pesquisador responsável

Como pesquisador responsável pelo estudo EFEITOS DE PRAXIAS IDEOMOTORAS NA QUANTIFICAÇÃO SÉRICA DO FATOR NEUROTRÓFICO DERIVADO DO CÉREBRO E SUA RELAÇÃO COM A MEMÓRIA NO PROCESSO DE ENVELHECIMENTO, declaro que assumo a inteira responsabilidade de cumprir fielmente os procedimentos metodologicamente e direitos que foram esclarecidos e assegurados ao participante desse estudo, assim como manter sigilo e confidencialidade sobre a identidade do mesmo.

Declaro ainda estar ciente que na inobservância do compromisso ora assumido estarei infringindo as normas e diretrizes propostas pela Resolução 466/12 do Conselho Nacional de Saúde - CNS, que regulamenta as pesquisas envolvendo o ser humano.

Natal de de 


\section{SOBRE OS AUTORES}

HUDDAY MENDES DA SILVA - Professor assistente da Faculdade Leão Sampaio no curso de Educação Física Mestre em Educação Física pela Universidade Federal do Rio Grande do Norte

JÔNATAS DE FRANÇA BARROS - Professor Titular no Departamento de Educação Física da Universidade Federal do Rio Grande do Norte e no Núcleo de Estudos em Educação e Promoção da Saúde e Projetos Inclusivos no Centro de Estudos Avançados e Multidisciplinares da Universidade de Brasília. Pós-doutor em Educação Inclusiva e Reabilitação pela Faculdade de Motricidade Humana da Universidade de Lisboa - Portugal

PATRICK RAMON STAFIN COQUEREL - Professor no Departamento de Educação Física da Universidade Federal do Rio Grande do Norte. Mestre em Ciências do Movimento Humano pela Universidade do Estado de Santa Catarina

FRANCISCO HOLANDA CAVALCANTE NETO - Professor pesquisador da Universidade Federal do Rio Grande do Norte; Professor do Centro de Ensino Positivo e Preceptor do curso de Educação Física da Universidade Potiguar. Mestre em Educação Física - Universidade Federal do Rio Grande do Norte

MARYANA PRYSCILLA SILVA DE MORAIS - Professora de Educação Física. Mestre em Educação Física pela Universidade Federal do Rio Grande do Norte

DENIZE MOTA NASCIMENTO - Graduanda em Educação Física pela Universidade Federal do Rio Grande do Norte

MÉRCIA VITORIANO DA COSTA - Professora de Educação Física. Graduada em Educação Física pela Universidade Federal do Rio Grande do Norte

GEYSA CACHATE ARAÚJO DE MENDONÇA - Professora de Educação Física. Mestranda em Educação pela Universidade Federal do Cariri

ANDRÉ RIBEIRO DA SILVA - Professor no Núcleo de Estudos em Educação e Promoção da Saúde e Projetos Inclusivos no Centro de Estudos Avançados e Multidisciplinares da Universidade de Brasília. Doutor em Ciências da Saúde pela Universidade de Brasília 


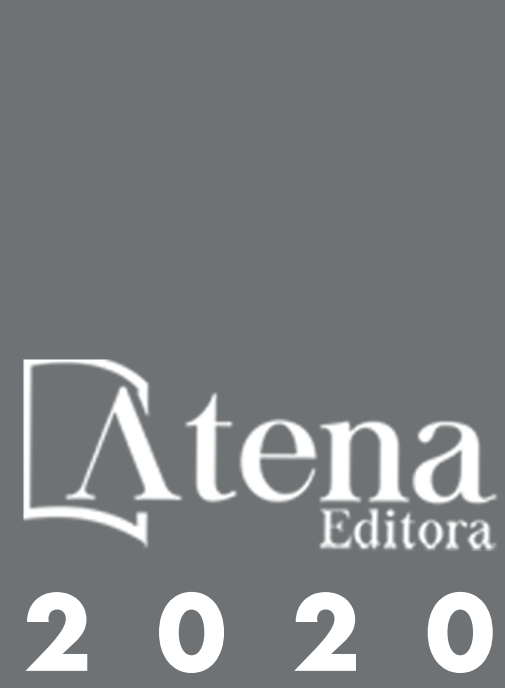

